\title{
Typical imaging finding of hepatic infections: a pictorial essay
}

\author{
Sonaz Malekzadeh ${ }^{1,2} \cdot$ Lucien Widmer $^{1} \cdot$ Faezeh Salahshour $^{3} \cdot$ Bernhard Egger $^{4} \cdot$ Maxime Ronot $^{5}$. \\ Harriet C. Thoeny ${ }^{1,2}$
}

Received: 25 April 2020 / Revised: 25 June 2020 / Accepted: 4 July 2020 / Published online: 26 July 2020

(c) The Author(s) 2020

\begin{abstract}
Hepatic infections are frequent in clinical practice. Although epidemiological, clinical and laboratory data may suggest hepatic infection in certain cases, imaging is nearly always necessary to confirm the diagnosis, assess disease extension and its complications, evaluate the response to treatment, and sometimes to make differential diagnoses such as malignancies. Ultrasound (US) is usually the first-line investigation, while computed tomography (CT) and magnetic resonance imaging (MRI) provide better characterization and a more precise assessment of local extension, especially biliary and vascular. The purpose of this article is to describe the typical features and main complications of common hepatic infections. Familiarity with the radiological features of this entity can help suggest the correct diagnosis and the need for further studies as well as determine appropriate and timely treatment.
\end{abstract}

Keywords Hepatic infection $\cdot$ Liver imaging $\cdot$ Liver infection

\section{Introduction}

Hepatic infections are relatively common. The prognosis varies and depends on the clinical context, the etiology of the underlying infection as well as when appropriate treatment is started. The clinical presentation ranges from chronic indolent forms to more aggressive lesions that are associated with a high mortality, especially in vulnerable or immunocompromised patients. The non-specific clinical symptoms of liver infections, including fever, abdominal discomfort, and nausea, highlight the importance of imaging with ultrasound (US), computed tomography (CT), and magnetic resonance imaging (MRI) to obtain a correct and

Sonaz Malekzadeh

soonazmalakzadeh@gmail.com

1 Department of Diagnostic and Interventional Radiology, Fribourg Cantonal Hospital, Fribourg, Switzerland

2 Faculty of Medicine, University of Fribourg, Fribourg, Switzerland

3 Department of Diagnostic and Interventional Radiology, Imam Khomeini Hospital, Tehran, Iran

4 Department of Surgery, Fribourg Cantonal Hospital, Fribourg, Switzerland

5 Department of Radiology, AP-HP, HUPNVS, Beaujon Hospital, Clichy, France prompt diagnosis. Although the imaging features of liver infections may be characteristic and sometimes lead directly to a correct diagnosis, clinical, laboratory and imaging findings are usually needed to make a final diagnosis. Imaging-guided fine-needle aspiration may also occasionally be required. Besides its central diagnostic role, imaging is important during follow-up of hepatic infections to monitor response to treatment.

The aim of this pictorial review article is to describe the most common imaging features of hepatic infections, categorized into bacterial, fungal, viral, and parasitic infections (Table 1). We also describe typical radiological findings to differentiate infections from other pathologies. Typical imaging features are summarized in Table 2. Chronic viral liver infection is beyond the scope of this article and will not be discussed.

\section{Bacterial infections}

\section{Pyogenic liver abscess}

Although pyogenic abscesses are often polymicrobial, Escherichia coli and Klebsiellae pneumoniae are the most frequently isolated pathogens $[1,2]$. While the cause of pyogenic abscess can usually be determined, no obvious cause is 
Table 1 Overview of infectious agent, sub-classifications, and organisms

\begin{tabular}{lll}
\hline $\begin{array}{l}\text { Types of infectious } \\
\text { cause }\end{array}$ & Sub-classifications & Organisms \\
\hline Bacterial & Pyogenic abscess & Polymicrobial \\
& & Escherichia coli \\
& Klebsiella pneumoniae \\
& Bacterial granulomatous disease & Mycobacterium tuberculosis \\
& & Brucella species \\
Acute viral & Bartonella species \\
& & Hepatitis A, B, C, D and E virus \\
Fungal & Human immunodeficiency viruses \\
& & Candida albicans \\
Parasitic & Histoplasma capsulatum \\
& Echinococcus species \\
& Infection of hepatic vessels & Entamoeba histolytica \\
& Infection of bile ducts & Schistosoma species \\
& & Fasciola species \\
& Ascaris lumbricoides \\
& Clonorchis sinensis \\
\hline
\end{tabular}

found in up to $20 \%$ of cases, which are known as cryptogenic $[3,4]$. The most common cause of a cryptogenic pyogenic abscess is the hypervirulent $K$. pneumoniae, which is associated with aggressive inflammatory disease and additional sites of infection in other organs [5, 6]. Surprisingly, it has a more favorable outcome than pyogenic abscesses, mainly because the former occur in immunocompetent patients [7]. Four main mechanisms can favor hepatic abscesses. First, they can be the result of hematogenous dissemination of gastrointestinal infections via the portal vein or disseminated sepsis via the hepatic artery. Bile infection, favored by duct obstruction from various etiologies including stones, neoplasms, and strictures (ascending cholangitis, pancreatic cancer, inflammatory bile duct diseases) is frequently observed. Moreover, biliary stents and bilio-digestive anastomosis are also iatrogenic predisposing factors for pyogenic liver abscesses [8, 9]. Finally, hepatic infection by continuity, such as hepatic abscess from cholecystitis or direct introduction of bacteria into the liver parenchyma, such as during hepatic biopsy or surgery, and superinfection of pre-existing hepatic lesions, e.g., cysts or necrotic liver lesions, are other routes of liver abscesses [10]. Classically, pyogenic liver abscesses are pus-containing uni- or multilocular lesions surrounded by a fibrotic capsule.

\section{Ultrasonography}

On US, the appearance varies depending on the size and content of the abscess and ranges from a well or ill-defined tiny hypoechoic nodule to a large hypoechoic lesion with septa and debris [11].

\section{Computed tomography}

The same appearance may be observed on CT with the characteristic "double target sign," defined as early arterial enhancement of the inner wall of the abscess and progressive enhancement of the outer layer [12]. The entire lesion is surrounded by segmental geographic or peripheral transient perfusion disorders, identified as regions with early arterial phase enhancement and iso-attenuation on portal venous and delayed phases [13]. These perfusion disorders are related to perilesional venule stenosis, due to edema and infiltration by inflammatory cells (Fig. 1). On CT pyogenic abscesses may also present as multiple tiny hypoattenuating lesions with peripheral rim enhancement that sometimes coalesce to form larger lesions, a feature referred to as the "cluster sign" [14]. This is a typical feature in abscesses of biliary origin.

\section{Magnetic resonance imaging}

On MRI, the central pus is hyperintense on T2-weighted images (T2WI) and hypointense on T1-weighted images (T1WI), with impeded diffusion due to pus accumulation and the increased viscosity of pus on Diffusion-weighted (DW MRI) imaging. The inner and outer layers of the wall appear hypo- and hyperintense on T2WI, respectively. Although pyogenic abscesses usually appear to be fluid collections, they may also have a more solid appearance, mimicking primary or secondary hepatic tumors. This is often found in association with $K$. pneumoniae [15]. 


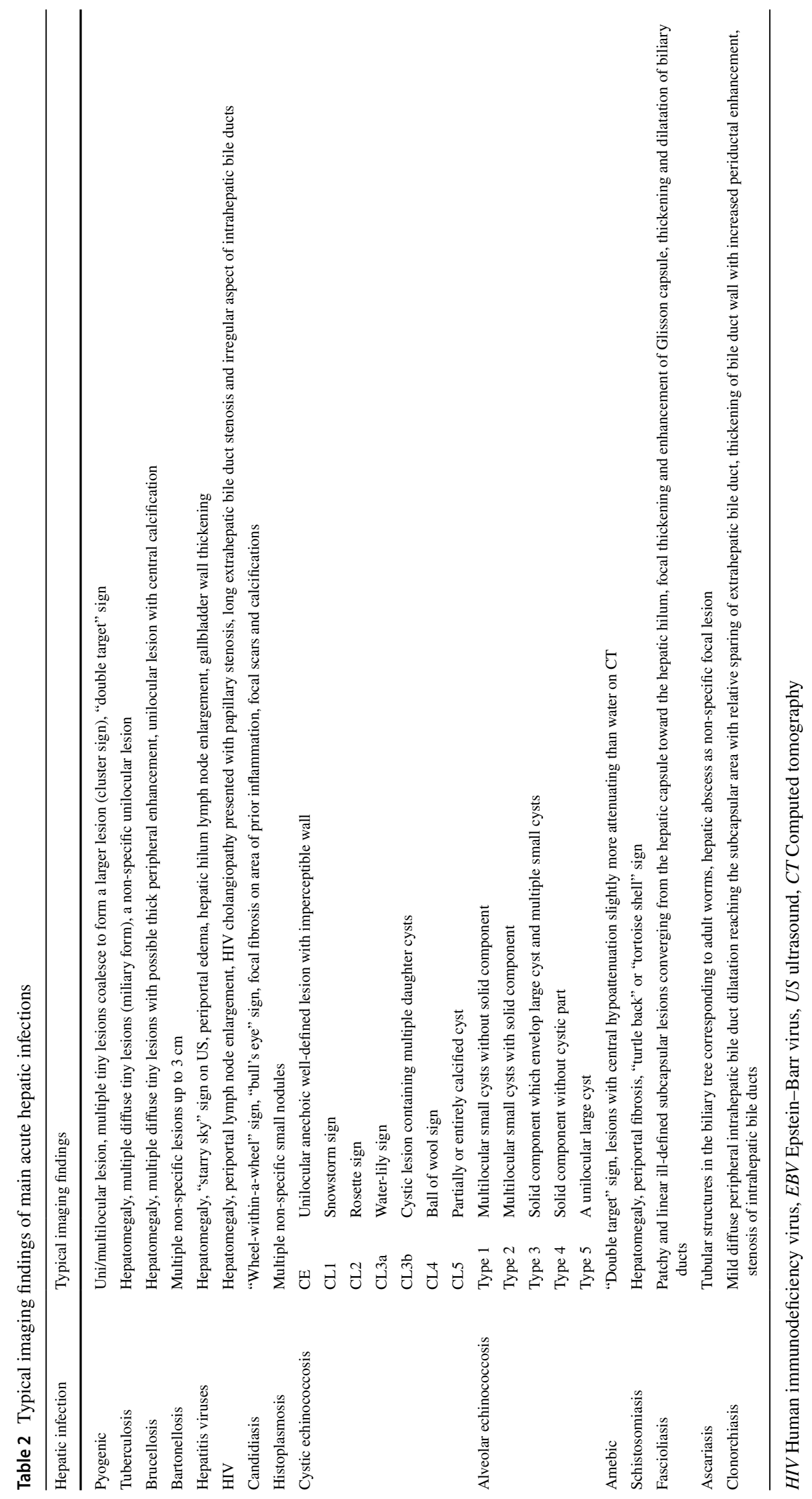




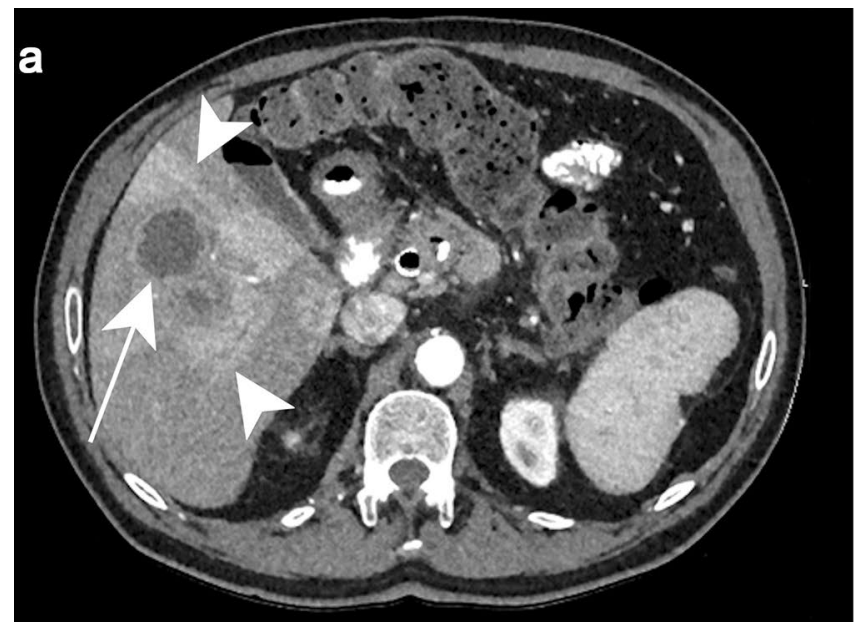

Fig. 1 Pyogenic abscess in a 60-year-old female patient with a history of chronic pancreatitis who presented with asthenia and fever. Axial arterial phase (a) and portal venous phase (b) contrast-enhanced CT show small clustering lesions with a dominant hypoattenuating lesion

\section{Differential diagnosis}

The main differential diagnosis of pyogenic abscesses includes primary or secondary hepatic tumors and amebic abscess. It is important to note that transient perilesional enhancement, which is more frequently associated with a pyogenic abscess, helps exclude hepatic tumors. Pyogenic liver abscesses may also be complicated by hepatic or portal vein thrombosis with a reported incidence of up to $42 \%$ $[16,17]$. Necrotic hepatocellular carcinoma associated with venous invasion can mimic a hepatic abscess complicated by cruoric venous thrombosis. However, venous thrombosis with luminal expansion, arterial phase intraluminal enhancement, and impeded diffusion of the venous structure suggests tumoral rather than cruoric venous thrombosis. Furthermore, the associated colon involvement supports amebic infection. However, the percutaneous approach is usually warranted for the diagnosis and therapeutic purposes.

\section{Tuberculosis}

Hepatic involvement in tuberculosis can occur from pulmonary or miliary tuberculosis or less frequently via portal vein from gastrointestinal lesions [18]. Hepatic tuberculosis can be local (tuberculous primary complex with caseous necrosis of the hepatic hilar lymph nodes) or miliary, a part of a generalized disease. The latter is the most common form of liver tuberculosis. [19]. Tuberculoma can also develop and correspond to the enlargement and confluence of miliary foci or nodular development of tuberculous foci.

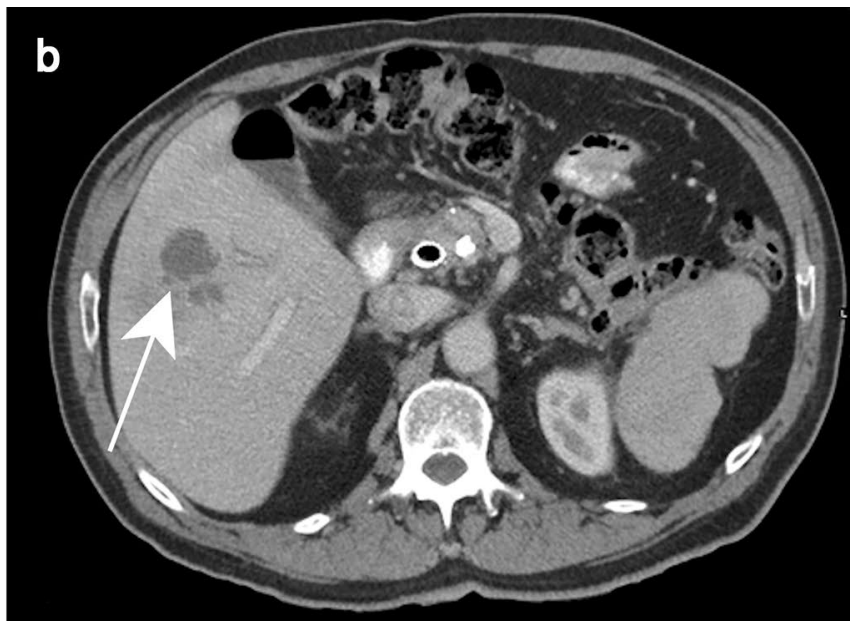

in segment $\mathrm{V}$ of the liver (white arrows) corresponding to pyogenic hepatic abscesses. Altered perfusion disorder is observed as geographic areas of hyperattenuation peripheral to the hepatic abscesses (white arrowheads), clearly visualized on arterial phase (a)

\section{Ultrasonography}

On US, the presentation of miliary hepatic involvement includes hepatomegaly with a diffuse hyperechoic aspect to the liver parenchyma with or without small diffuse hypoechoic lesions [20]. In the macronodular tuberculosis, single or multiple focal lesions with variety of appearance ranging from hyper- to hypoechoic lesions can be observed (Fig. 2a, b). Both hyper- and hypoechoic features are thought to represent different phases of disease corresponding to the degree of necrosis [21].

\section{Computed tomography}

On CT, the miliary form is observed as the multiple small hypoattenuating foci with discrete enhancing rim after contrast administration [22]. The macronodular lesions are detected as hypoattenuating lesions ranging from 14 to 45 HU on unenhanced CT, with tiny peripheral enhancement after contrast administration while the central part remains unchanged [23]. Calcifications can be observed in both miliary and macronodular forms [19].

\section{Magnetic resonance imaging}

On MRI, the miliary form is detected as multiple tiny lesion which are hypointense on T1WI and hyperintense on T2WI. The macronodular form presents hypo- or hyperintense central area on T2WI, with a hypointense rim [22, 24]. As observed with pyogenic abscess, liver tuberculosis can demonstrate impeded diffusion on DW MRI, making it difficult to differentiate from pyogenic abscess. 


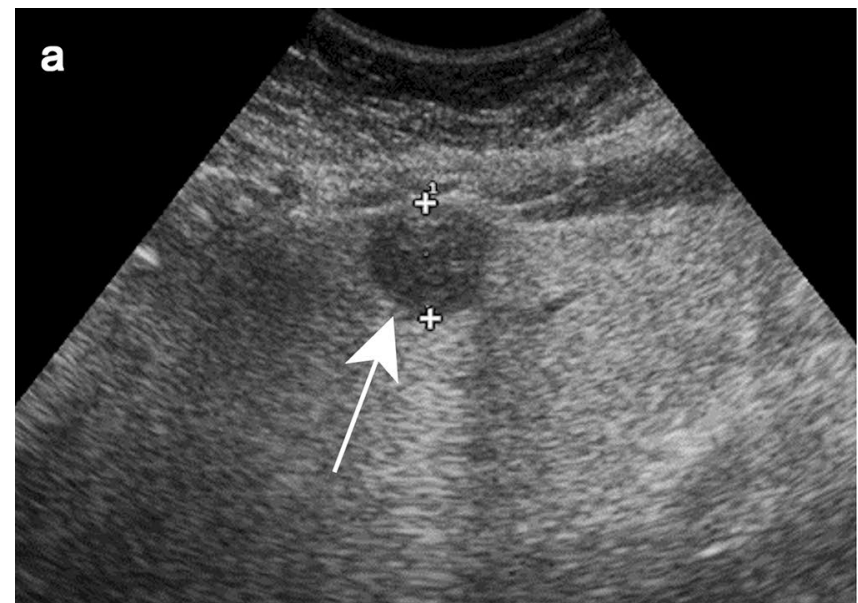

Fig. 2 Liver tuberculosis in a 49-year-old female patient with asthenia and loss of weight without fever. Ultrasound a demonstrates a focal well-defined subcapsular hypoechoic lesion in segment

\section{Differential diagnosis}

The main differential diagnosis of miliary form includes lymphoma, metastatic lesions, sarcoidosis, and fungal infections. For the macronodular form, primary and metastatic hepatic lesions as well as pyogenic abscesses constitute the main differentials. Imaging is usually insufficient to make the definitive diagnosis and percutaneous biopsy is needed.

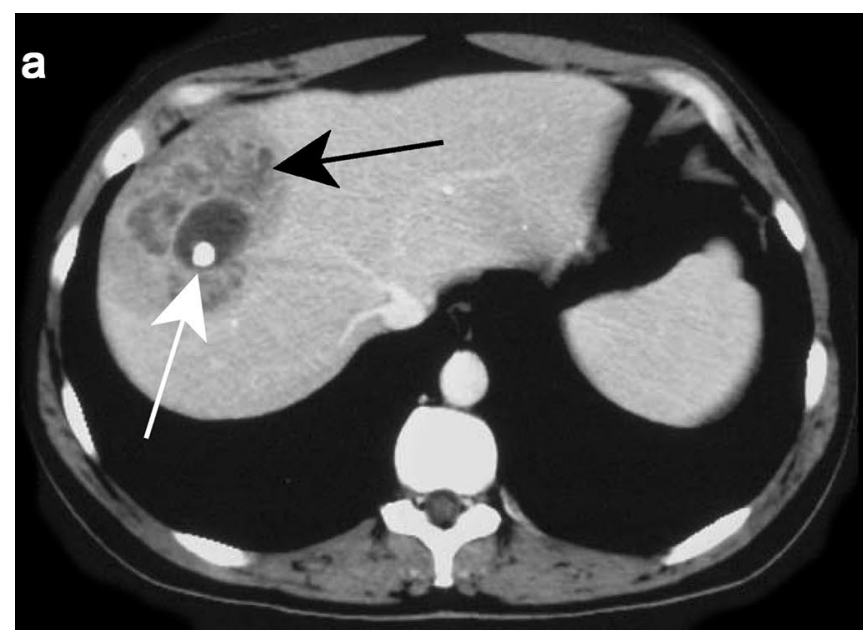

Fig. 3 Brucellosis in a 42-year-old male patient with evening fever and sweating. Contrast-enhanced axial CT image a shows a heterogeneous lesion with enhanced contours (black arrow), showing a central hypoechoic fluid component and a calcium deposit (white arrow). Axial contrast-enhanced T1-weighted image b shows enhancement

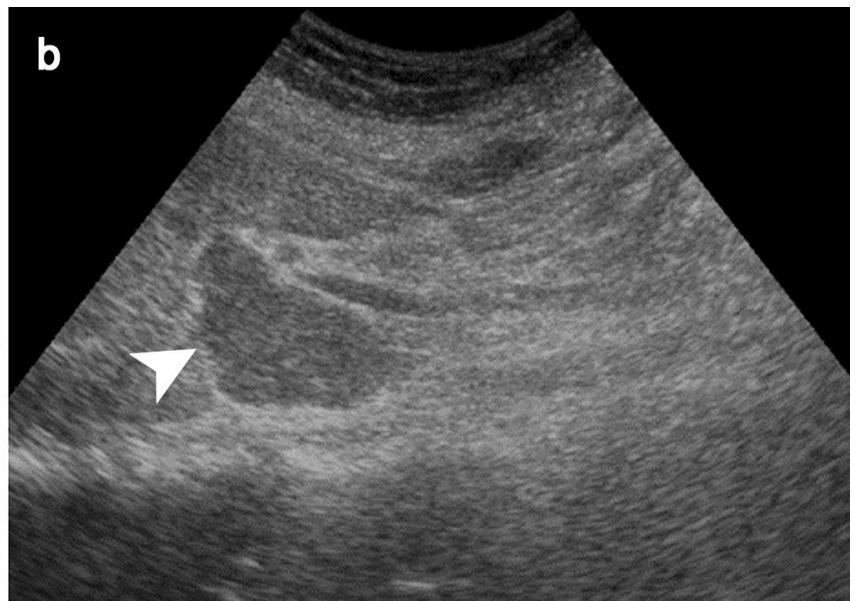

III (white arrow). Enlarged lymph node (white arrowhead) is also observed in the porta hepatis (b) (Courtesy of Dr. Suzan Elhakiem, Ibn Sina Hospital, Khartoum, Sudan)

\section{Brucellosis}

Hepatomegaly is a typical feature of hepatic abscess in brucellosis. A suppurative hepatic abscess is also a rare finding in these cases. Solitary abscesses normally present with a central calcification [25].

\section{Ultrasonography}

Hepatic abscesses from brucellosis may be solitary or miliary. Solitary lesions are seen as heterogeneous, welldelineated lesions, while miliary abscesses are seen as multiple hypoechoic hepatic subcentrimetric lesions which

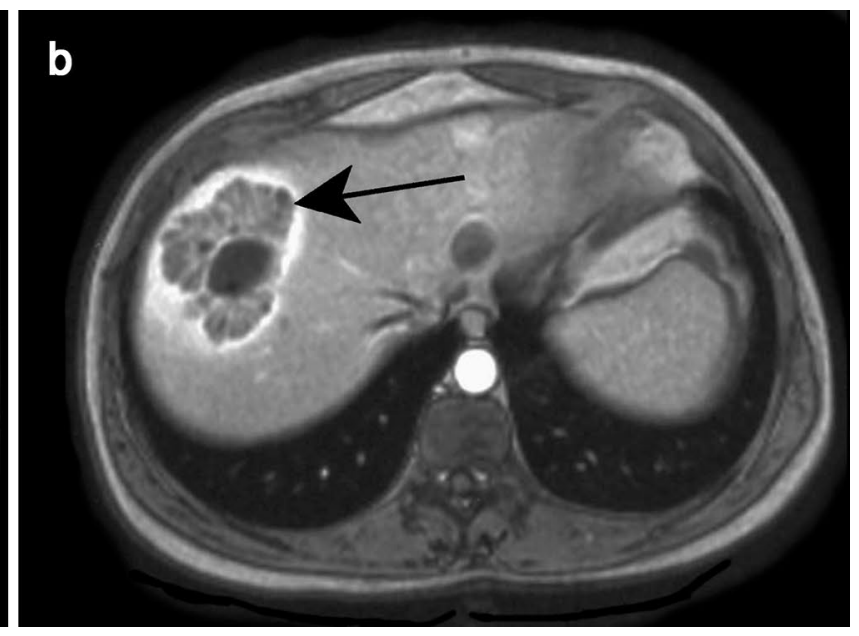

of the peripheral tissular areola (black arrow) and central saccular formation with fluid, surrounded by an intermediary heterogeneous component. Reprinted from Sisteron et al. [27], with permission from Elsevier 
are difficult to be differentiated from tuberculosis, candidiasis or lymphoma.

\section{Computed tomography}

Hepatic abscesses are hypoattenuating with thick peripheral enhancement on contrast-enhanced CT (Fig. 3a). Perilesional transient perfusion disorder, like that found in pyogenic abscesses, may also occur with brucellosis.

\section{Magnetic resonance imaging}

These abscesses are hyperintense on T2WI on MRI. It is important to note that thickened peripheral enhancement, up to $15 \mathrm{~mm}$, has been described in these abscesses on after contrast administration (Fig. 3b) [26, 27].

\section{Differential diagnosis}

When miliary, they should be differentiated from tuberculosis, candidiasis and lymphoma while pyogenic abscesses remain the differential diagnosis for solitary form.

\section{Bartonellosis}

Bartonellosis, also known as "cat-scratch disease", is usually associated with painful lymphadenopathy near the cat bite or scratch site. In the presence of liver involvement, multiple necrotizing granulomas, measuring up to $3 \mathrm{~cm}$, can be detected throughout the liver parenchyma.

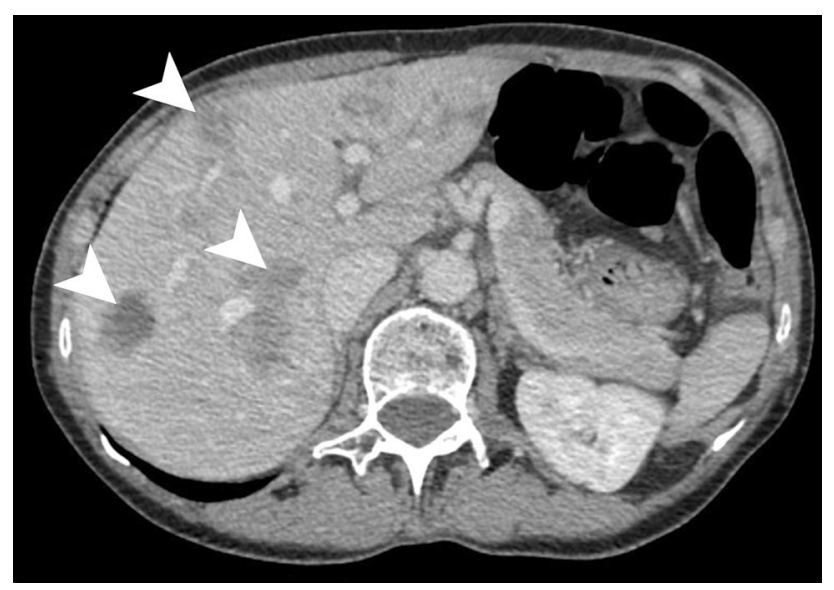

Fig. 4 Bartonellosis in a 65-year-old female patient treated for autoimmune hepatitis. Axial contrast-enhanced CT demonstrates hypoattenuating ill-defined lesions are scattered throughout the liver parenchyma (white arrowheads)

\section{Ultrasonography}

Necrotizing granulomas are seen as non-specific hypoechoic nodules throughout the liver parenchyma.

\section{Computed tomography}

These lesions are hypoattenuating on precontrast CT. These nodules may remain hypoattenuating after contrast administration (Fig. 4) or demonstrate iso-attenuation and sometimes rim enhancement [28].

\section{Magnetic resonance imaging}

On MRI, they are hypointense on T1WI and hyperintense on T2WI with the same enhancement as that of CT [29].

\section{Differential diagnosis}

Although it may be difficult to differentiate bartonellosis from lymphoma, fungal infection, sarcoidosis, tuberculosis or brucellosis on cross-sectional imaging, a history of cat contact in an immunocompetent child or young adult can be helpful.

\section{Acute viral infection}

\section{Viral hepatitis}

Acute hepatic viral infections are mostly caused by hepatitis $\mathrm{A}, \mathrm{B}, \mathrm{C}, \mathrm{D}$, and $\mathrm{E}$ viruses [30]. Ingestion of contaminated food or water and contact with blood or other body fluid of infectious person are the common ways of transmission. Although the radiological features of acute hepatitis are non-specific, imaging is usually performed to exclude other diseases with the same clinical signs, such as biliary obstruction or diffuse liver metastases.

\section{Ultrasonography}

On US, acute hepatitis usually presents with hepatomegaly, decreased hepatic echogenicity, as well as a relative increase in portal wall echogenicity, known as the "starry sky" sign [11].

\section{Computed tomography}

On CT, hepatomegaly, heterogeneous hepatic contrast enhancement on arterial phase images, well-defined parenchymal zones with low attenuation, periportal hypoattenuation, or hepatic hilum lymph node enlargement can be observed [31]. Gallbladder wall thickening may also be 


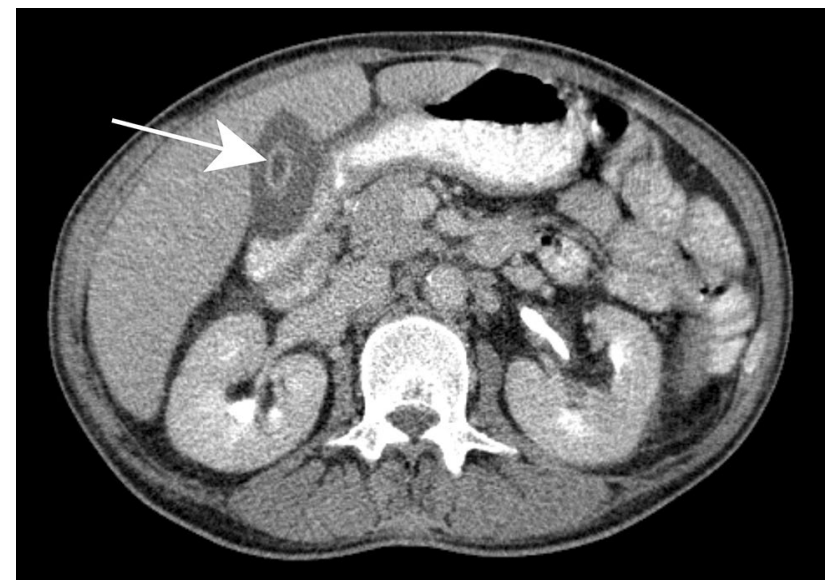

Fig. 5 Acute viral hepatitis in a 59-year-old male patient with jaundice and elevated liver enzymes due to hepatitis A infection. Axial contrast-enhanced CT shows a contracted gallbladder with a thick hypoattenuating edematous wall and an enhancing mucosal layer (white arrow)

observed during acute hepatitis (Fig. 5) and should not be misinterpreted as acute cholecystitis [32]. Non-distended gallbladder and an absence of gallstones are the additional findings which suggest a diagnosis of acute hepatitis. Nevertheless, the liver may have a normal appearance on CT with serologically proven viral hepatitis.

\section{Magnetic resonance imaging}

The findings on MRI are the same as those on CT with a hyperintense periportal halo on T2WI and a hypointense T1WI image [33].

However, the diagnosis of viral hepatitis is mainly based on clinical and laboratory data rather than imaging findings.

\section{Differential diagnosis}

The imaging findings of viral hepatitis such as hepatomegaly and periportal edema are non-specific and differential diagnosis includes metabolic disease, passive hepatic congestion, autoimmune hepatitis and drug-induced hepatitis.

\section{Human Immunodeficiency Virus (HIV)}

Liver involvement in patients with acquired immunodeficiency syndrome (AIDS) is not rare and frequently these patients suffer also from chronic viral infections such as hepatitis B and C.

\section{Ultrasonography}

On US, gallbladder wall thickening with biliary ducts wall thickening and dilatation can be encountered [11].

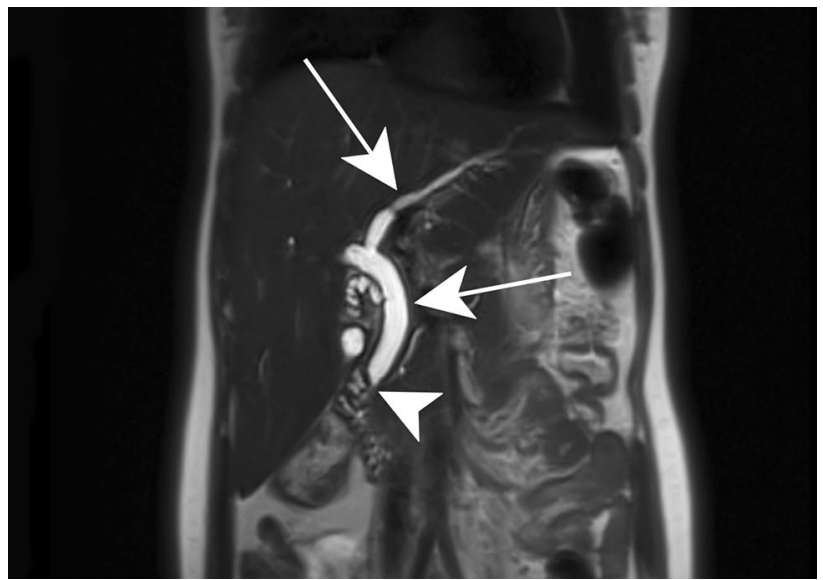

Fig. 6 HIV-related cholangiopathy in a 16-year-old female patient. Coronal T2-weighted image demonstrates intrahepatic and extrahepatic bile duct dilatation (white arrows) due to papillary stenosis (white arrowhead), a common finding in this disease

\section{Computed tomography}

Hepatomegaly and periportal lymphadenopathy are usually observed which are non-specific. In rare cases, focal steatosis and acalculous cholecystitis can also be seen [34].

\section{Magnetic resonance imaging}

Because HIV hepatopathies are frequently associated with biliary and pancreatic disorders, contrast-enhanced MRI with Magnetic resonance cholangiopancreaticography (MRCP) has been proposed in a single session to evaluate biliary tract lesions as well as liver and pancreatic parenchymal anomalies [35]. Imaging findings include biliary stenosis involving long extrahepatic segments, papillary stenosis (Fig. 6), and acalculous cholecystitis [35].

\section{Differential diagnosis}

As for viral hepatitis, the imaging findings for liver involvement in HIV such as hepatomegaly and periportal lymphadenopathy are non-specific. However, the primary sclerosing cholangitis is considered to be the main differential diagnosis for HIV cholangiopathy.

\section{Fungal infection}

\section{Hepatic candidiasis}

Invasive systemic candidiasis is a significant cause of morbidity and mortality in immunosuppressed patients, 
especially those receiving chemotherapy or with hematological malignancies.

\section{Ultrasonography}

Four US patterns of hepatosplenic candidiasis have been described [36]. The first pattern has a "wheel-within-awheel" appearance with a central hypoechoic area of necrosis and fungal debris, surrounded by a hyperechoic zone of inflammatory cells. A hypoechoic rim is found at the periphery, representing fibrosis. The second pattern is a bull's eye configuration with a central hyperechoic nidus surrounded by a hypoechoic rim. In general, this pattern develops in patients with active fungal infection and a relatively normal white blood cell count. The third pattern is the most common and includes a uniformly hypoechoic nodule representing fibrosis that has developed in an area of prior inflammation, which is non-specific and can simulate metastases or lymphoma. The fourth pattern, which occurs in later stages of infection, consists of hyperechoic foci with different degrees of posterior acoustic shadowing, representing scars or calcifications.

\section{Computed tomography}

On CT, the microabscesses are seen as small, round, hypoattenuating lesions, in a miliary pattern [37]. Also, a "wheelwithin-a-wheel" pattern, as observed by US, can be detected.

\section{Magnetic resonance imaging}

On MRI, the untreated nodules are markedly hyperintense on T2WI and minimally hypointense on T1WI (Fig. 7) with

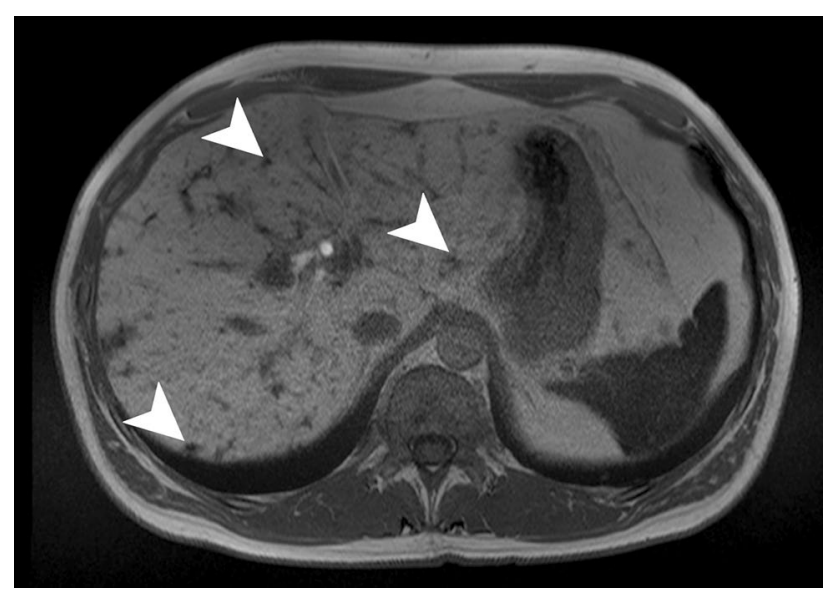

Fig. 7 Candidiasis in a 65-year-old male patient with acute myeloblastic leukemia. Axial contrast-enhanced T1-weighted image on hepatobiliary phase illustrates multiple tiny hypointense lesions throughout the liver parenchyma (white arrowheads) (Courtesy of Dr. Luisa Paulatto, Beaujon Hospital, Clichy, France) moderate enhancement after contrast administration [38]. After treatment, the microabscesses develop to granuloma with various imaging patterns according to the phase after treatment.

\section{Differential diagnosis}

Tuberculosis, sarcoidosis, metastases and lymphoma are the main diagnoses to be differentiated from hepatic candidiasis. A chest-X-ray may be conclusive to exclude tuberculosis and sarcoidosis. In patients with a known history of malignancy, the hepatic lesions can be likely metastases. However, a secondary fungal infection should also be considered in this group of patients. Lymphoma is usually associated with supra- and infra-diaphragmatic lymphadenopathies. Nonetheless, in some cases the percutaneous biopsy is conclusive for the diagnosis.

\section{Hepatic histoplasmosis}

Histoplasmosis is caused by inhalation of Histoplasma capsulatum spores. It usually develops in immunodeficient patients, such as HIV-positive patients and transplant recipients [39]. The liver is rarely the primary site of infection but it is often involved in the course of a progressive disseminated disease, which usually originates in the lungs or upper respiratory tract. Imaging lacks sensitivity and specificity, and findings are similar to those in tuberculosis, candidiasis or other disseminated fungal diseases, with multiple small nodules in the liver parenchyma.

\section{Parasitic infections}

\section{Infection of the hepatic parenchyma}

\section{Echinococcosis}

Echinococcus granulosus and Echinococcus multilocularis cause cystic echinococcosis (CE) and alveolar echinococcosis (AE), respectively. While E. granulosus is more common, E. multilocularis is more invasive [40]. Infections occur by either ingestion of food or plants containing the eggs from the Echinococcus tapeworm or by direct contact with the main hosts, which are dogs (E. granulosus) and foxes (E. multilocularis) [41, 42]. The ingested embryos reach the portal venous system by invading the mucosal duodenal wall then embed the sinusoidal spaces and develop cysts.

\section{Echinococcus granulosus}

The mature cyst (i.e., hydatid cyst) of E. granulosus is composed of three layers. The outer layer or pericyst, mainly 
corresponds to the compressed adjacent hepatic parenchyma. The middle layer or ectocyst, is a translucent acellular layer allowing nutrition to pass to the endocyst, while the inner germinal layer produces the scolices, surrounding a fluidfilled central cavity $[43,44]$.

Ultrasonography The appearance of CE on imaging, which is best evaluated by US, depends on the stage of cyst growth, classified by WHO into the six following subgroups:

CL (cystic lesions): are well-defined, unilocular, anechoic lesions with an imperceptible wall.

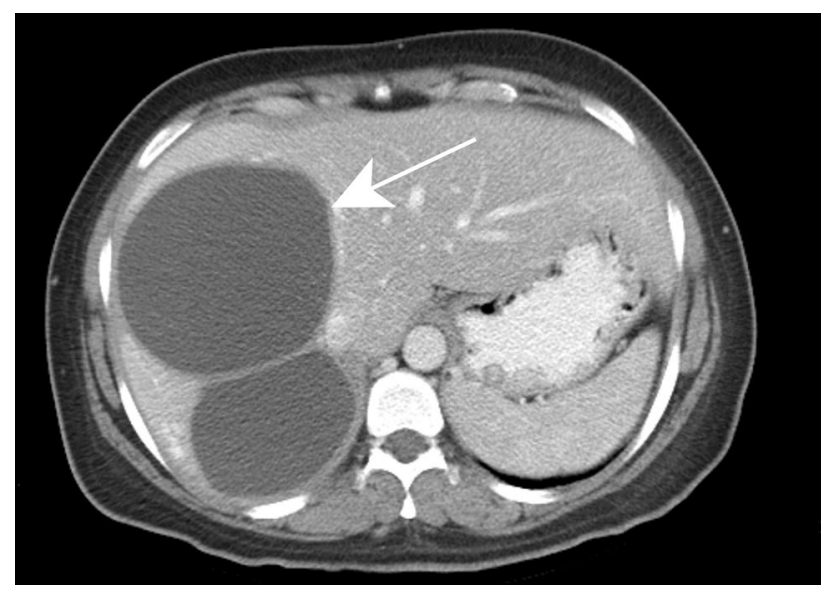

Fig. 8 Cystic echinococcosis type CL in a 32-year-old female patient with upper abdominal discomfort. Axial contrast-enhanced CT image shows two large cystic lesions with thin walls in segment VII and VIII of the liver (white arrow). Ultrasound (not shown) revealed an anechoic cyst with a double layered wall, no internal daughter cyst or detached membrane

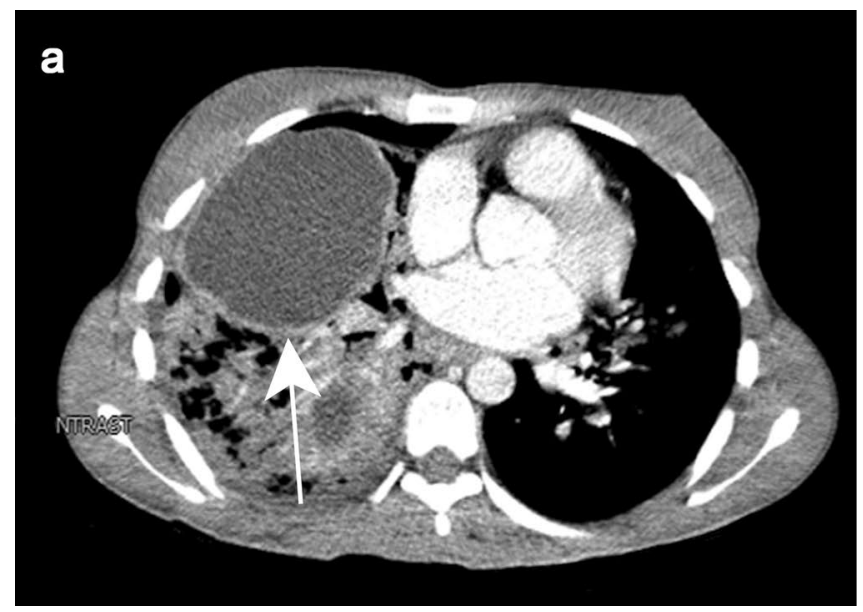

Fig. 9 Cystic echinococcosis type CE3a in a 27-year-old female patient with cough. Axial contrast-enhanced CT of the lower pulmonary parenchyma a reveals a pulmonary cyst in the middle lobe (white arrow) associated with a partial consolidation of the right
CE1: is an anechoic lesion with a perceptible doublelayer wall that contains dependent low-level echos called hydatid sand. Hydatid sand (free scolices produced by the endocyst) is mobile when the patient changes position, which is referred to as the "snowstorm" sign [11, 42, 45]. CE2: is a cystic lesion that contains multiple septa or multiple cystic lesions involving nearly the entire cystic cavity so that the walls of the cysts are very close to each other, with a "rosette" appearance.

CE3a: in these cases the germinal layer is detached from the pericyst, which remains intact and is seen floating in the cystic cavity, known as a "water-lily" sign $[41,44]$.

CE3b: is a cystic lesion that encases multiple daughter cysts. The daughter cysts are arranged peripherally in the cystic cavity which contains a solid-appearing matrix compared to the fluid in CE2.

CE4: presents as a heterogeneous mass that ranges from hypoechoic to hyperechoic on US, with no identifiable daughter cyst.

CE5: is a partially or entirely calcified cyst. When the cyst wall is calcified, it presents as a hyperechoic peripheral rim with acoustic shadow.

Computed tomography On precontrast $\mathrm{CT}$, the cyst wall usually appears as a hyperattenuating capsule that is nearly isoattenuating compared to the adjacent hepatic parenchyma following contrast administration [46]. CL is visualized as a well-defined, unilocular hypoattenuating lesion with thin wall (Fig. 8). The debris, when visible, shows no obvious contrast enhancement. The detached germinal layers are visible as serpiginous hyperattenuating structures (Fig. 9). The daughter cysts present as the hypoattenuating lesions with

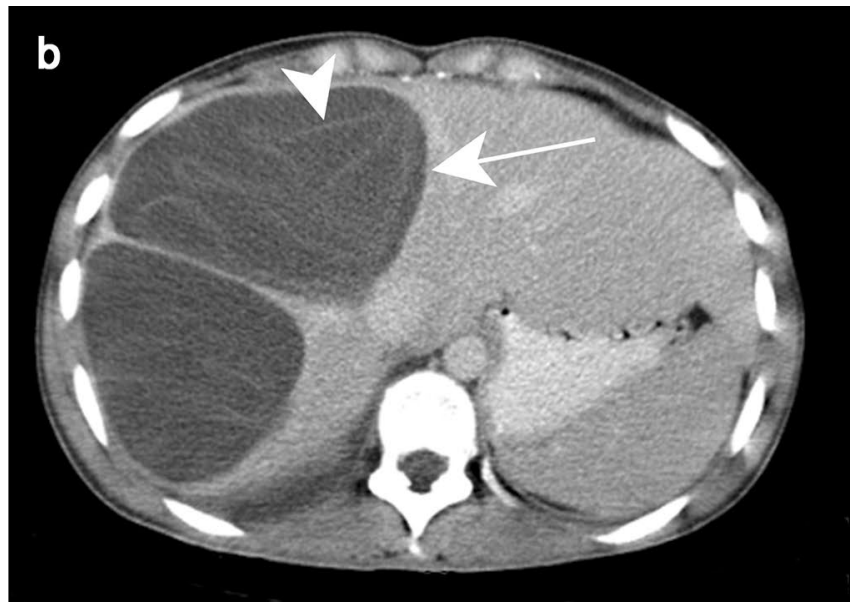

lower lobe. Axial contrast-enhanced CT of the upper abdomen b shows two hepatic cystic lesions (white arrow) with internal detached membranes ("water-lily" sign) (white arrowhead) 


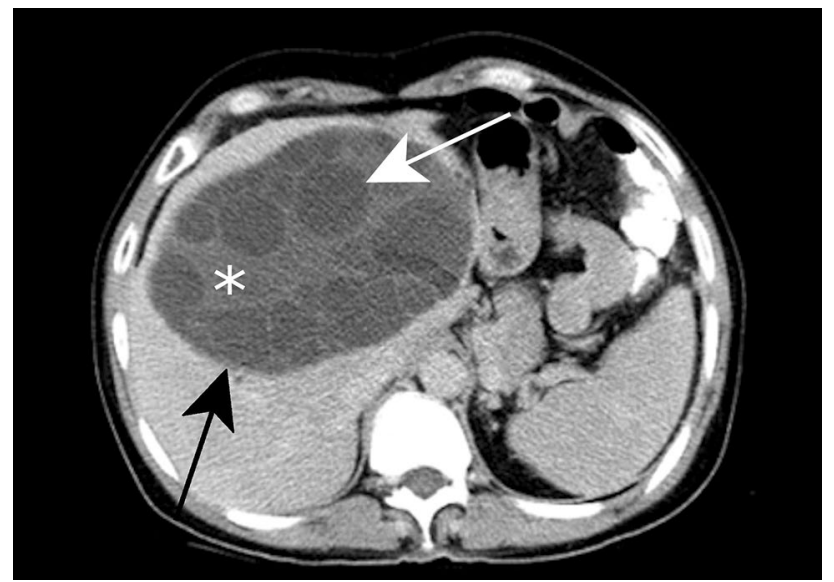

Fig. 10 Cystic echinococcosis type CE3b in a 54-year-old male patient with right upper quadrant pain. Axial contrast-enhanced CT reveals a large hepatic cyst in right hepatic lobe (black arrow) with solid matrix in the center (asterisk) and peripherally located daughter cysts (white arrow)

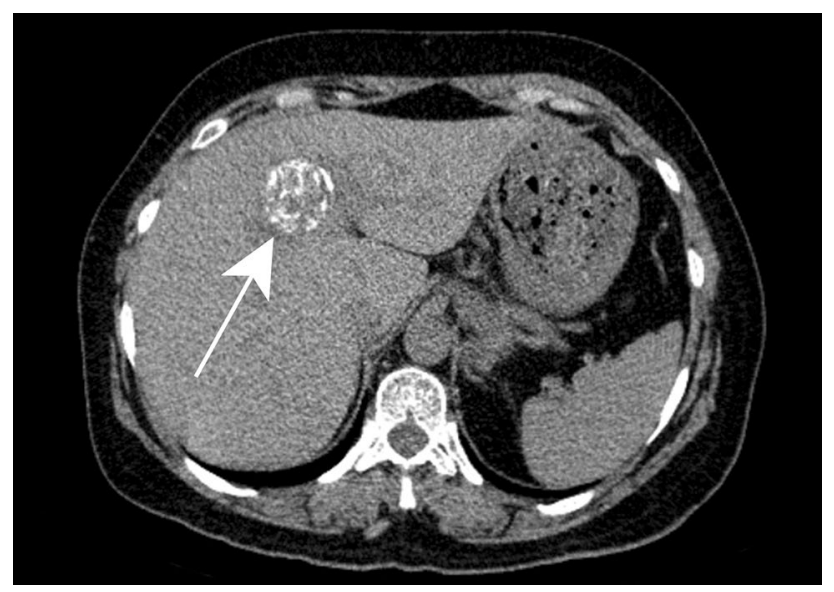

Fig. 11 Cystic echinococcosis type CE5 in a 50-year-old female patient with an incidental solid mass reported on ultrasound. Axial precontrast CT shows a round highly calcified lesion in segment IV (white arrow)

a density lower than the matrix of the cyst (Fig. 10). When the wall is calcified, it is well appreciated on CT (Fig. 11).

Magnetic resonance imaging On MRI the pericyst has a characteristic hypointense appearance, surrounding a markedly hyperintense T2WI and hypointense T1WI central cavity $[44,47,48]$. The daughter cysts are hyperintense and hypointense T2WI and T1WI, respectively, compared to the cyst matrix. The "ball of wool" sign, which is the characteristic feature of $\mathrm{CE} 4$, is a result of the detachment of the inner layer folding on itself so the lesion appears as a solid mass (Fig. 12). Calcifications are seen as the focal hypointense lesions on T2WI.

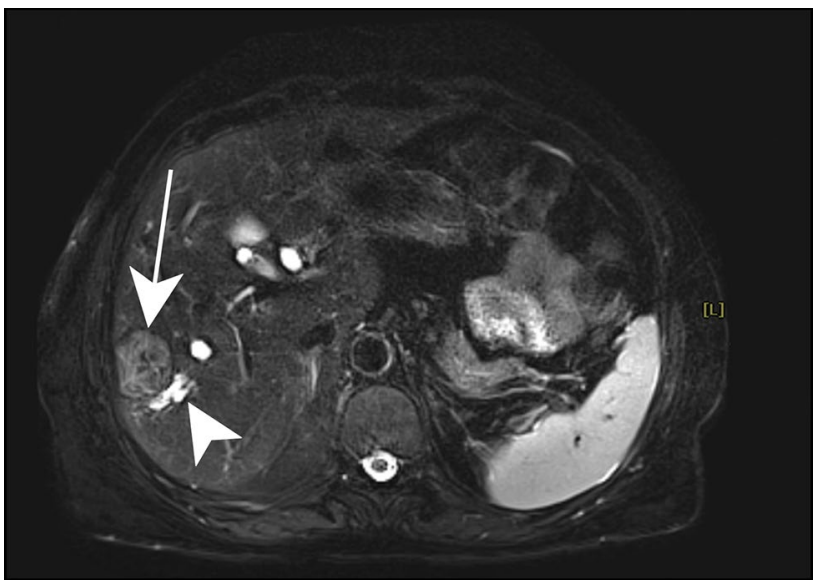

Fig. 12 Cystic echinococcosis type CE4 in a 62-year-old female patient with upper abdominal pain. Axial fat-suppressed T2-weighted image shows a well-defined subcapsular moderately hyperintense lesion (white arrow) with a characteristic "ball of wool" sign. An adjacent dilated intrahepatic bile duct is also noted (white arrowhead)

CL, CE1, and CE2 are active lesions, while CE4 and CE5 are inactive lesions. CE3 corresponds to transitional lesions which are degenerating cysts but containing viable protoscoleces $[49,50]$. Hydatid cysts may be associated with complications including superinfection, communicating rupture, external rupture and the mass effect of large hydatid cysts. Superinfection is associated with a gas-fluid level or gas bubble in the hydatid cyst, frequently surrounded by areas of transient perfusion disorders in the surrounding hepatic parenchyma, such as in pyogenic abscesses [51]. Fistula with a hollow viscera or the tracheobronchial tree may also lead to gas-fluid levels which may be confounded with cyst superinfection [46, 52]. Communicating rupture is a cystic rupture into the biliary tree which may result in the passage of hydatid sand, a floating membrane from the germinal layer or daughter cysts into the biliary ducts, as well as fluid-fluid levels containing bile in the hydatid cyst. The latter are seen as fat droplets in the cyst with marked hypoattenuation on CT, and signal dropout on opposed phased gradient echo T1WI. This feature in not entirely specific for cystic rupture, since fatty transformation may occur in old cysts.

External rupture is direct rupture of a cyst into the peritoneal or pleural cavity frequently via the bare area of the gastrohepatic ligament (Fig. 13). Finally, hydatid cysts can have a mass effect on the adjacent biliary or vascular structures. Chronic biliary obstruction and vascular compression, such as portal vein compression, can lead to hepatic segmental or lobar atrophy as well as secondary Budd-Chiari syndrome due to the mass effect on the hepatic veins (Fig. 14). 


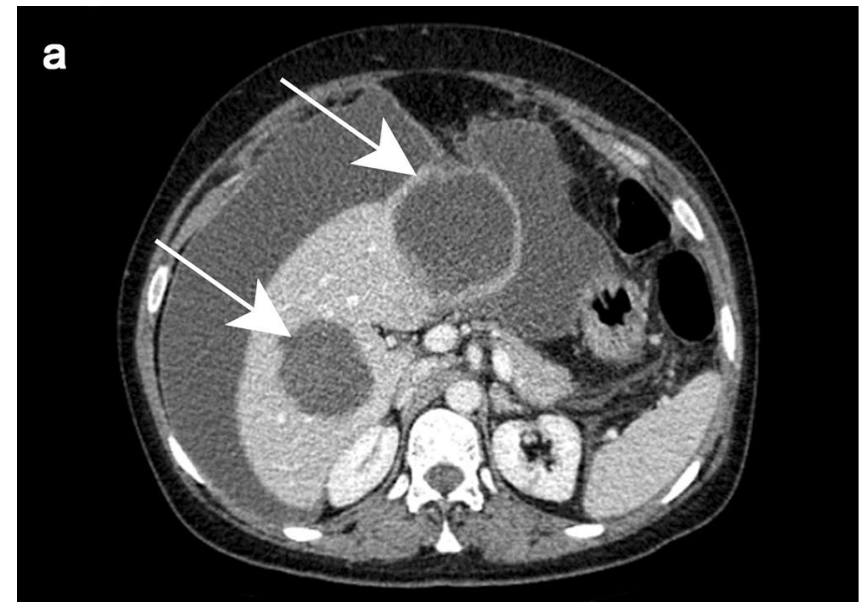

Fig. 13 Peritonitis due to a ruptured hydatid cyst in a 45-year-old female patient with acute upper abdominal pain. Axial contrastenhanced CT of the upper abdomen (a) demonstrates two hepatic cysts with irregular borders in the right and left liver lobe (white

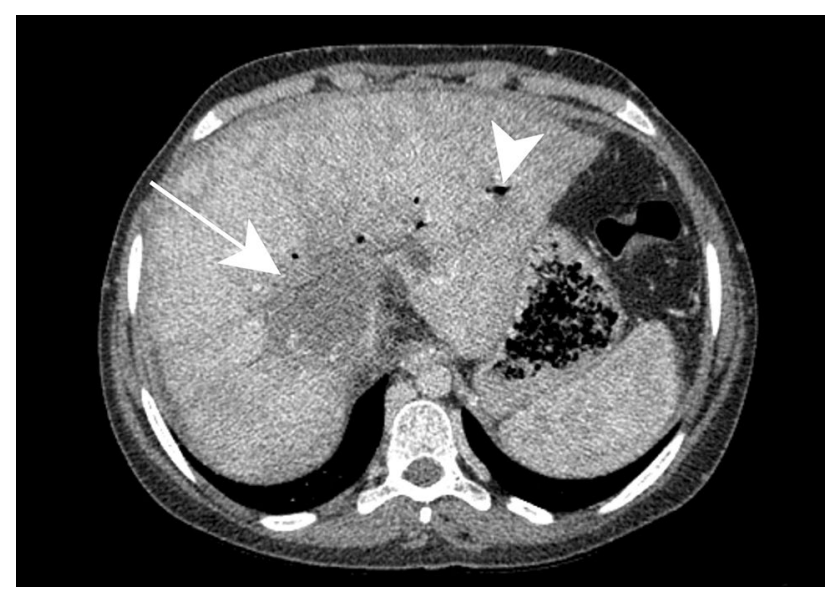

Fig. 14 Budd-Chiari syndrome secondary to compression of liver out-flow by the hydatid cyst in a 20 -year-old female patient. Hypertrophy of the caudate lobe with inhomogeneous mottled liver appearance is indicative of Budd-Chiari syndrome. Axial delayed phase contrast-enhanced CT shows a deformed cystic lesion in the deep portion of segments VII and VIII of the liver (white arrow) associated with pneumobilia secondary to previous sphincterotomy (white arrowhead)

Differential diagnosis Various congenital, inflammatory, infectious, and neoplastic cystic lesions can mimic different stages of CE. However, the typical imaging features of CE along with the serological information are usually helpful to discriminate $\mathrm{CE}$ from its counterparts.

The treatment of the CE depends on the stage of the cyst, including medical treatment, percutaneous approach recognized as PAIR (puncture, aspiration, injection, and reaspiration), surgical strategy, and watch-and-wait [53]. Medical treatment, PAIR, and catheterization are usually reserved

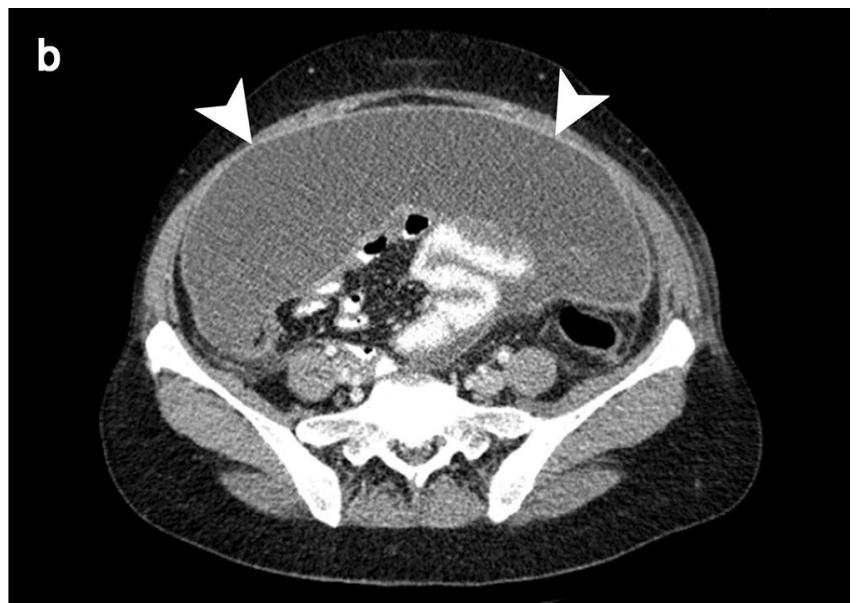

arrows); the latter reaches the anterior liver surface. Axial contrastenhanced CT of lower abdomen (b) shows a significant amount of intraperitoneal fluid with a thickened enhancing peritoneum (white arrowheads)

for CE1 and CE3a, whereas modified catheterization and surgery are preferred methods for CE2 and CE3b. CE4 and CE5 can be controlled by watch-and-wait as they are considered to be inactive $[50,54]$.

\section{Echinococcus multilocularis}

AE includes small, multilocular confluent cysts associated with solid components that demonstrate exogenous growth invading the adjacent hepatic parenchyma. A large cystic component is also frequently observed. Small cysts include metacestodal vesicles, while large cysts are composed of liquefaction necrosis. Moreover, solid components encompass calcification and coagulation necrosis.

\section{Ultrasonography}

The two most frequent US findings of AE include a heterogeneous lesion with irregular borders and a large hypoechoic lesion. In the former, the heterogeneous lesion comprises the hypoechoic (necrosis and active parasitic tissue) and hyperechoic areas (fibrosis and calcification) with irregular borders indicating the invasive nature of the lesion while the latter is demonstrated as a central necrosis surrounded by hyperechoic fibrotic tissue [50].

\section{Computed tomography}

On CT, AE is usually presented as heterogeneous lesion containing hypoattenuating areas of necrosis and active parasitic 


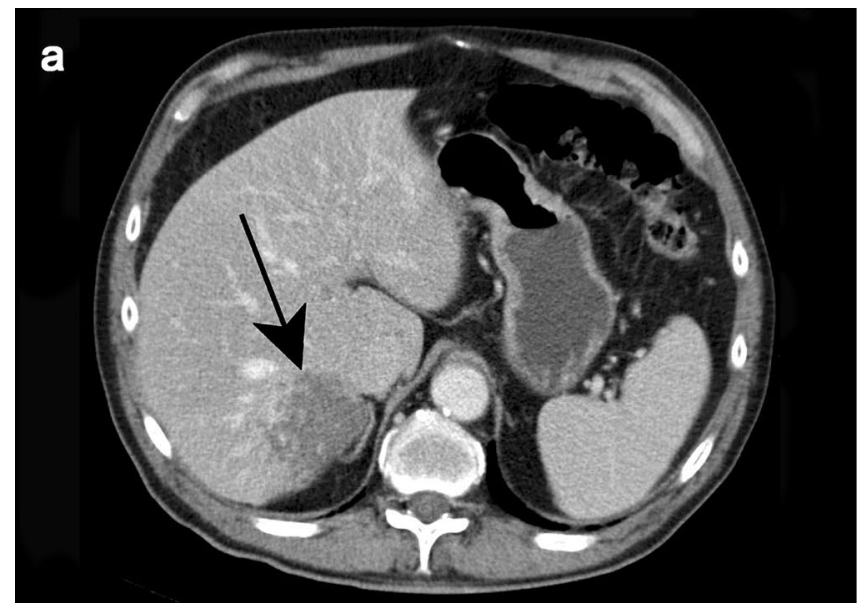

Fig. 15 Alveolar echinococcosis incidentally detected in a 75-yearold male patient. Axial contrast-enhanced CT a shows an ill-defined subcapsular hypoattenuating lesion in segment VII of the liver (black arrow). Axial fat-suppressed T2-weighted image $\mathbf{b}$ further character-

tissue with scattered calcification with no obvious enhancement after contrast administration (Fig. 15a) [50].

\section{Magnetic resonance imaging}

Kodama et al. classified AE into five groups on MRI based on cystic and solid components, distribution and contrast enhancement (Table 2) [55]. Typical findings include peripheral arrangement of multilocular cysts and slight or no contrast enhancement of the solid component (Fig. 15b). While cystic components are markedly hyperintense on T2WI, the solid component can range from hypo- to hyperintense on T2WI $[55,56]$.

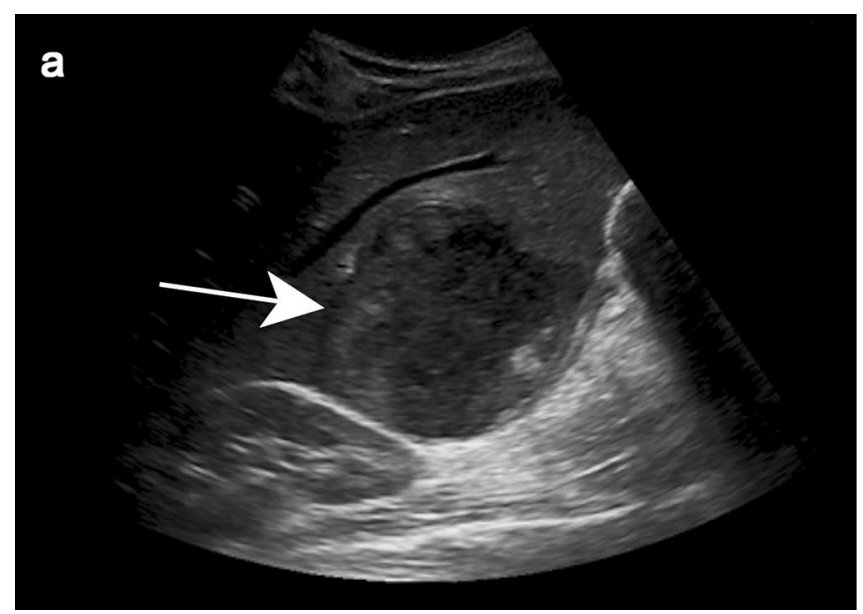

Fig. 16 Amebic abscess in a 57-year-old male patient who presented with fever of unknown origin and right upper abdominal pain with a recent history of travel to Africa. Ultrasound a demonstrates a large

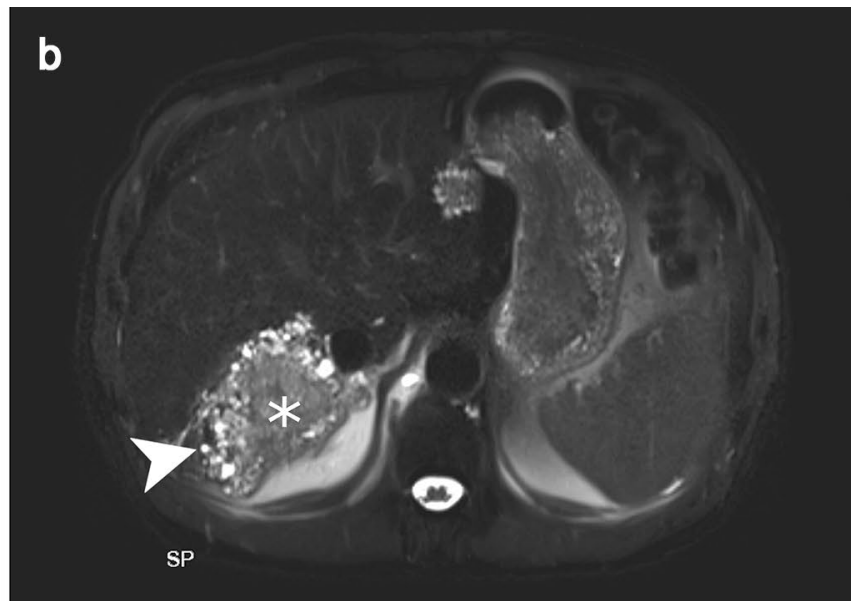

izes this lesion as multiple tiny cystic lesions (white arrowhead) surrounding a solid component corresponding to type 3 of alveolar echinococcosis

\section{Differential diagnosis}

The heterogeneous form of $\mathrm{AE}$ can be misinterpreted as primary and secondary hepatic malignancies and the large necrotic AEs should be differentiated from pyogenic and amebic abscesses.

\section{Amebic abscess}

Liver amebic abscess is the most common site of extraintestinal involvement of amebiasis, the infection of the large bowel by Entamoeba histolytica. It occurs in less than $1 \%$ of patients with $E$. histolytica infection [11,57]. Amebic abscess is usually a solitary unilocular cyst that is frequently

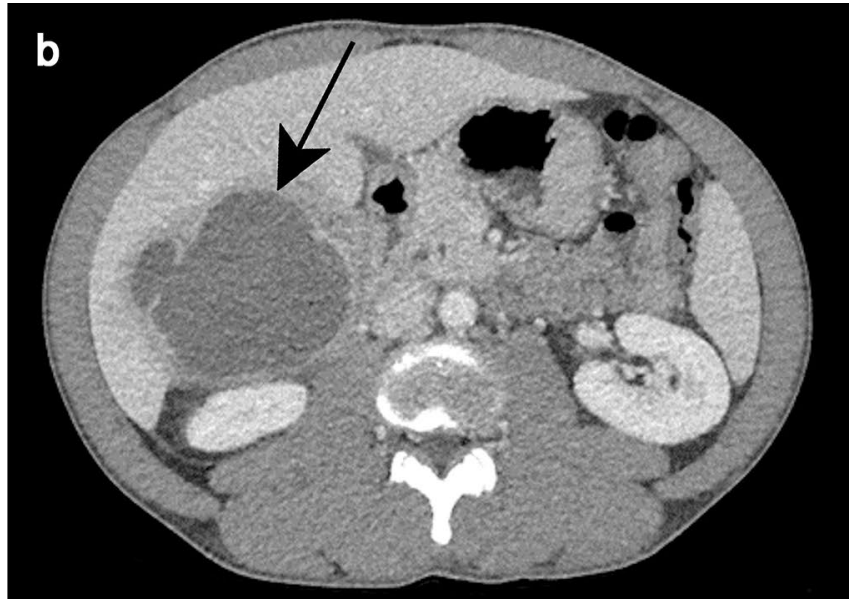

relatively well-delineated lesion with a heterogeneous solid-appearing content (white arrow). Axial contrast-enhanced CT shows the "double target sign" (black arrow) 
located in the right hepatic lobe, especially the posterior segment.

\section{Ultrasonography}

On US, it is demonstrated as a hypoechoic, well-delineated lesion containing low-level echoes that correspond to debris or hemorrhage (Fig. 16a).

\section{Computed tomography}

On precontrast $\mathrm{CT}$, an amebic abscess is hypoattenuating but slightly more attenuating than water, and varies in density between 10 and 20 Hounsfield units [HU] with a thick peripheral capsule up to $1.5 \mathrm{~mm}$ in diameter $[11,58]$. The capsule is enhanced after contrast administration and surrounded by peripheral hypoattenuation, known as the "double target sign," similar to that observed with pyogenic abscesses (Fig. 16b) [43, 44].

\section{Magnetic resonance imaging}

On MRI, the central area is hypointense and hyperintense on T1WI and T2WI, respectively. The peripheral capsule is enhanced after contrast administration, and the lesion is surrounded by a hyperintense T2WI peripheral area [59].

\section{Differential diagnosis}

The appearance of an amebic abscess on imaging is nearly indistinguishable from that of a pyogenic abscess. However, a solitary abscess is more likely to be an amebic abscess compared to pyogenic abscess which is typically multiple. Also, the association of colon wall thickening that spares the ileum is highly suggestive of an amebic abscess. Furthermore, extrahepatic complications, such as pleural or pericardial effusion, and perihepatic collections, are more frequent with amebic than with pyogenic abscesses. Nonetheless, the definitive diagnosis is usually made through a combination of imaging, serological, microbial, and percutaneous aspiration data [60]. Metronidazole is the treatment of choice for amebic abscesses and aspiration or percutaneous drainage is considered for larger abscesses with high risk of rupture or in the case of failure to medical treatment [61].

\section{Infection of hepatic vessels}

\section{Schistosomiasis}

Five species of Schistosoma cause human infection, and $S$. mansoni and S. japonicum are the most common causes of hepatic infection [62]. Schistosomes penetrate the skin to reach the bowel lumen where they lodge and release eggs into the mesenteric vein, gaining access to the portal system [44]. Schistosoma eggs cause a chronic inflammatory granulomatous reaction in the portal system, causing periportal fibrosis. Thus, the radiological features in the acute phase are non-specific, including hepatosplenomegaly and focal nodular liver lesions. In the chronic phase, fibrosis bands are observed surrounding the portal system. With $S$. mansoni, this is mainly observed when eggs are lodged in the proximal portion of the portal venous system while with $S$. japonicum, smaller eggs tend to lodge in the more distal portal veins [43].

\section{Ultrasonography}

On US, the fibrosis bands are defined as a hyperechoic mantle encompassing the anechoic portal vein called the "bull's eye" sign (Fig. 17) [11]. Common hallmarks of the chronic phase are a cirrhosis-like appearance with heterogeneous parenchyma and irregular contours.

\section{Computed tomography}

Periportal fibrosis presents as hypoattenuating bands on precontrast CT and with delayed phase contrast enhancement

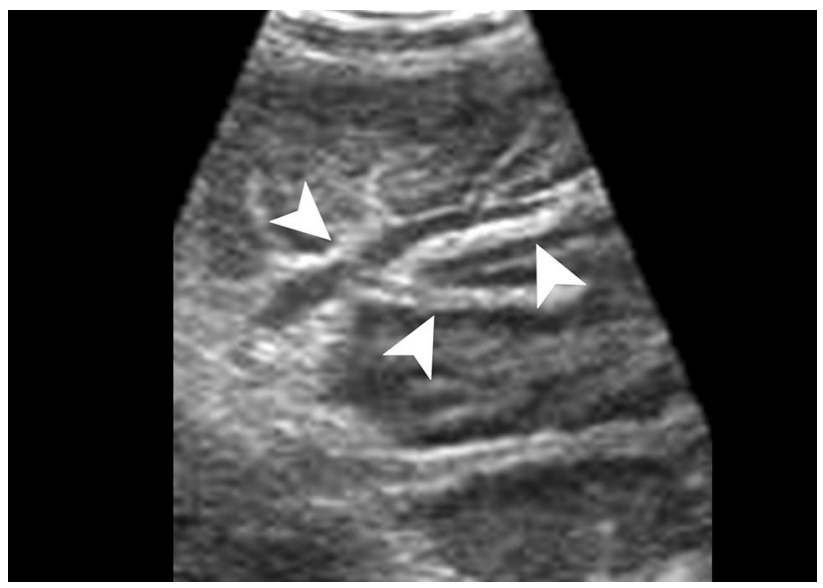

Fig. 17 Hepatic schistosomiasis in a 20 -year-old male patient with a history of gastrointestinal bleeding from 1 year ago. Ultrasound demonstrates a marked diffuse periportal thickening as a hyperechoic mantle encompassing the anechoic portal vein (white arrowheads) (Courtesy of Dr. Suzan Elhakiem, Ibn Sina Hospital, Khartoum, Sudan) 
showing polygonal hypoattenuating structures surrounding areas of normal parenchyma [63]. The hypoattenuating peripheral septa observed with $S$. japonicum tend to calcify later in the disease and are seen as calcified septa, perpendicular to the hepatic capsule, called the "turtle back" sign or "tortoise shell" feature [63].

\section{Magnetic resonance imaging}

On MRI, periportal and polygonal fibrosis are hypointense on T1WI and hyperintense on T2WI with delayed contrast enhancement.

\section{Differential diagnosis}

A cirrhosis-like appearance of chronic schistosomiasis should be differentiated from other causes of cirrhosis. However, calcification and periportal fibrosis, which are typical findings in schistosomiasis, are not common with other causes of cirrhosis.

\section{Infection of bile ducts}

\section{Fascioliasis}

Fasciola hepatica and Fasciola gigantica are parasites that are responsible for fascioliasis infection [64]. Sheep and cattle are the definitive hosts, while humans may be infected by ingesting contaminated water or freshwater plants [65]. There are two phases to fascioliasis infection, including a parenchymal (migratory phase) and biliary phase. During the parenchymal phase, juvenile flukes reach the peritoneal space by invading the small bowel wall, then reach the hepatic parenchyma by penetrating the hepatic capsule.
They migrate to the biliary tree from the subcapsular space in linear tracts, converging toward the portal triads. During the biliary phase, the flukes mature in the small biliary ducts and produce eggs. Although the imaging findings depend on the phase of infection, both phases can be present simultaneously.

Ultrasonography During the hepatic phase, US shows confluent hypoechoic ill-defined subcapsular lesions [66]. In the biliary phase, intra and extrahepatic bile duct dilatation is observed. A mobile intraductal parasite, when visible, is characteristic [67].

Computed tomography On CT, ill-defined linear or patchy hypoattenuating subcapsular and periportal lesions that may converge from the hepatic capsule towards the hepatic hilum are observed (Fig. 18a, b) [68]. As observed on US, biliary ducts dilatation, gallbladder wall thickening and hilar lymphadenopathy can be seen. Focal thickening and hyperenhancement of the Glisson capsule may also be observed [69].

Magnetic resonance imaging The lesions are hypointense on T1WI and hyperintense on T2WI, due to their inflammatory nature. Thickening and dilatation of the biliary tree similar to cholangitis can be observed during the biliary phase. The living, mobile parasite may sometimes be detected in the biliary tree as a biliary tree filling defect without contrast enhancement.

Differential diagnosis Confluent tiny hypoattenuating lesions can mimic primary and secondary liver malignancy or pyogenic abscess. In addition, the biliary ducts wall thickening and enhancement observed with fascioliasis should
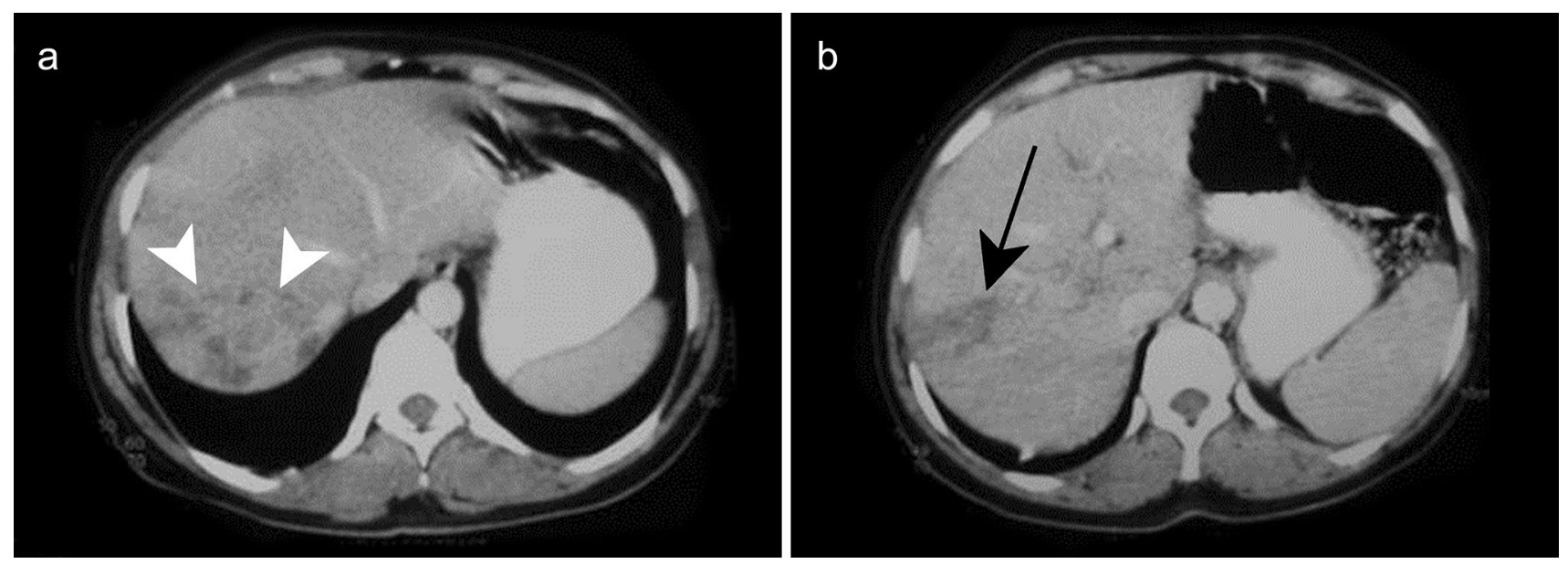

Fig. 18 Fascioliasis in a 42-year-old female patient with right upper abdominal pain and low-grade fever. Axial contrast-enhanced CT (a, b) show patchy ill-defined hypoattenuating lesions with subcapsular (white arrowheads) and periportal distribution (black arrow) 
be discriminated from other causes of cholangitis such as biliary stone.

\section{Ascariasis}

Ascariasis is a common infection caused by Ascaris lumbricoides in endemic areas. The adult worms mainly live in the jejunum, but may occasionally reach the ampulla of Vater due to altered small bowel motility [70]. Mechanical obstruction of the intrahepatic and common bile ducts by adult worms leads to cholangitis, cholecystitis, jaundice, and less frequently pancreatitis [71]. A hepatic abscess is also observed, although this is rare and thought to be due to a superinfection of the dead adult worm in the hepatic parenchyma [72].

Ultrasonography On US, the radiological diagnosis of biliary involvement is mainly based on direct visualization of adult worms seen as a long tubular echogenic structure measuring up to $30 \mathrm{~cm}$ in the biliary tree. A longitudinal anechogenic line, representing the gastrointestinal tract of the worm in the center of the tubular structure, can also be seen [73]. A hepatic abscess presents as a non-specific hypoechoic focal lesion, usually with an ill-defined border [72].

Computed tomography Intra- and extrahepatic bile ducts dilatation can be depicted and the worm is seen as a linear filling defect in the bile duct (Fig. 19a, b)

Magnetic resonance imaging As observed with other imaging modalities, the worm is seen as a linear filling defect in the bile duct on MRCP (Fig. 19c). Liver abscess resembles abscess with other pathogenic agents: a focal lesion hyperintense $\mathrm{T} 2$ and hypointense $\mathrm{T} 1$.

\section{Clonorchiasis}

Clonorchiasis is caused by chronic infection of Clonorchis sinensis following ingestion of raw freshwater fish [74]. When ingested, the cyst is freed by gastric juices and then reaches the biliary tree via the ampulla of Vater. Larva mature and lodge in the intrahepatic biliary ducts, although they may also reside in the extrahepatic bile ducts and gallbladder [74]. Flukes are leaflike structures ranging from 8 to $15 \mathrm{~mm}$ long and may lodge sporadically or grouped in the biliary tree, causing obstruction and an inflammatory reaction of the biliary epithelium. This chronic inflammatory reaction results in adenomatous hyperplasia, lymphocyte infiltration, ductal stenosis, and periductal fibrosis [75]. The imaging features of clonorchiasis are mainly based on the obstructive and inflammatory-induced effects.
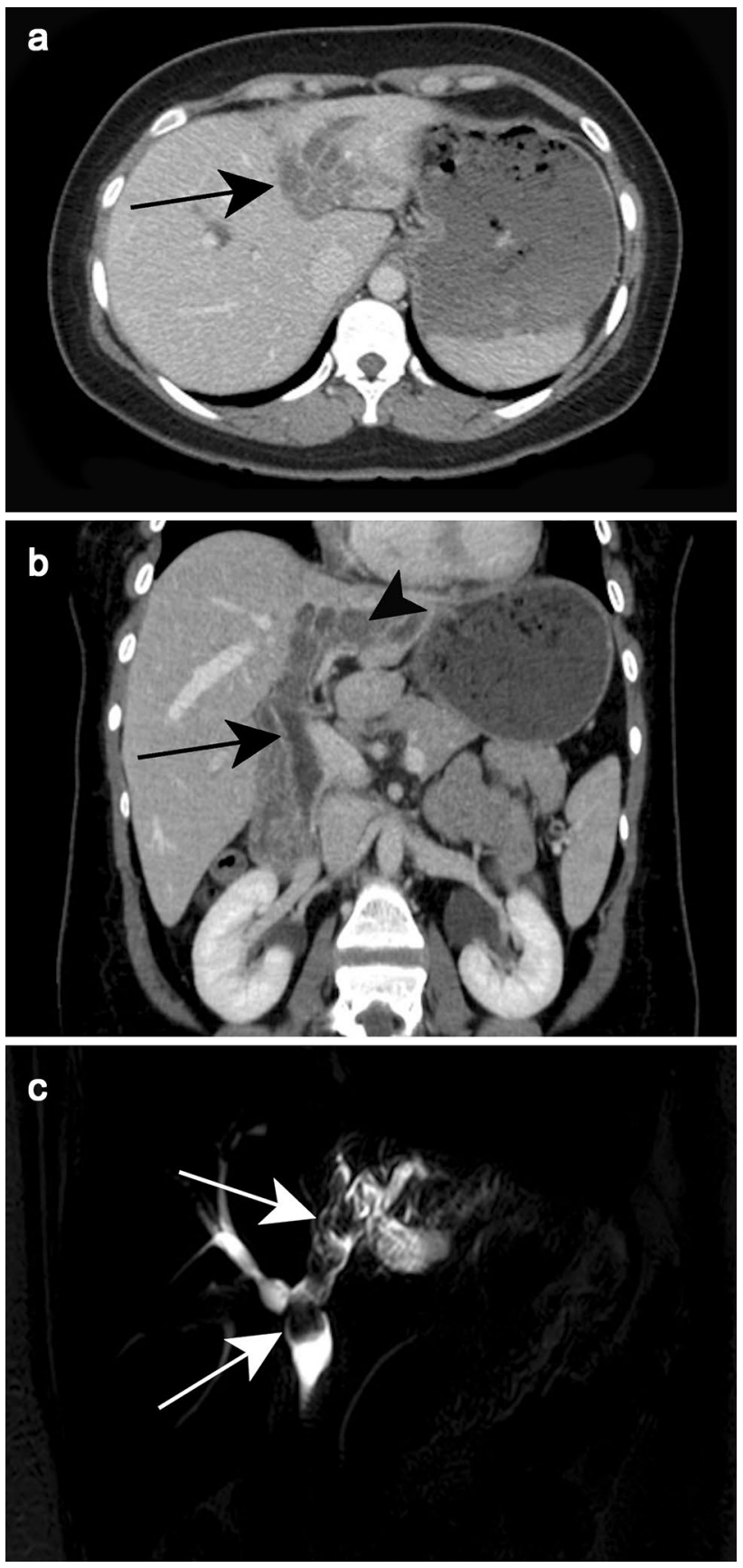

Fig. 19 Ascariasis in a 36-year-old male patient. Axial and coronal reformatted contrast-enhanced CT (a, b) show intrahepatic and extrahepatic bile duct dilatation (black arrows). Note intrahepatic bile ducts filled with structures more attenuating than bile (black arrowhead), indicating adult worms. Oblique coronal single-shot fast spinecho MR cholangiogram (c) shows adult worms as serpiginous and nodular filling defects in the left intrahepatic and extrahepatic bile ducts (white arrows)

Ultrasonography Mild diffuse peripheral intrahepatic bile duct dilatation reaching the subcapsular area, with relative sparing of the extrahepatic bile ducts, is characteristic [76]. Hyperechoic bundles surrounding the intrahepatic bile 


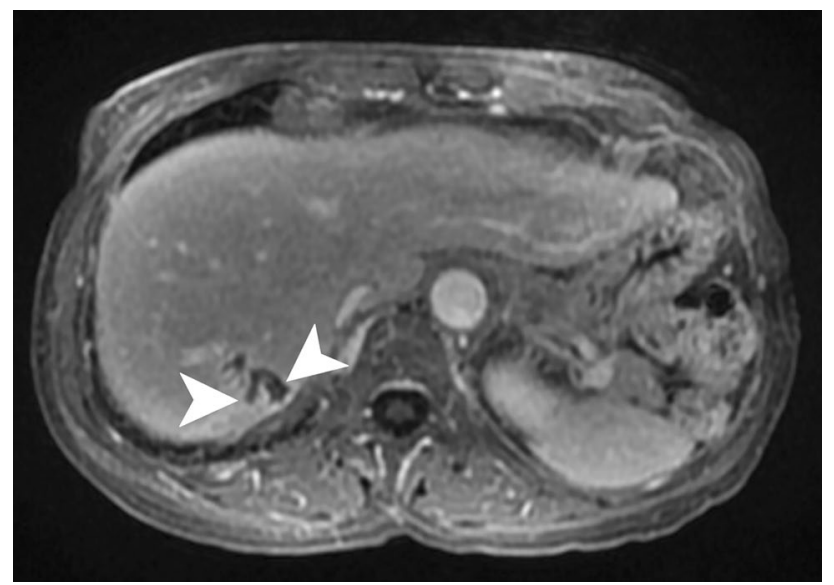

Fig. 20 Clonorchiasis in a 74-year-old female patient with recurrent cholangitis. Axial contrast-enhanced fat-suppressed T1-weighted image shows intrahepatic bile ducts dilatation in segment VII reaching the subcapsular zone (white arrowheads)

ducts are present, indicating thickening of the wall ducts. Mature flukes may be observed as elliptical or filamentous hyperechoic structures in the biliary tree [77, 78]. Stenosis of the intrahepatic bile ducts can also be detected as the disease progresses.

Computed tomography A thickened biliary duct with increased periductal enhancement is usually seen.

Magnetic resonance imaging As on US, intrahepatic bile ducts dilatation reaching the subcapsular area is observed (Fig. 20). MRCP shows elliptical or filamentous filling defects corresponding to mature flukes whose appearance can be differentiated from round or oval intraductal stones [76]. Cholangiocarcinoma is a well-known complication of clonorchiasis [78].

\section{Differential diagnosis}

It includes primary sclerosing cholangitis and recurrent pyogenic cholangitis.

\section{Conclusion}

Imaging plays a central role in the diagnosis of hepatic infectious diseases. Although hepatic infections may have typical imaging features, additional epidemiological, clinical, and laboratory information is frequently needed to confirm the diagnosis. However, in some cases, imaging-guided aspiration is the only diagnostic tool that can determine the causative agent or eliminate non-infectious pathologies. Although different imaging modalities, including US, CT, and MRI, may identify certain unique features of hepatic infections,
US is the primary diagnostic tool due to its low cost, the absence of radiation exposure and optimal biliary tree evaluation. However, in the presence of non-specific clinical symptoms, CT is usually performed to characterize hepatic lesions as well as to evaluate extrahepatic expansion or the presence of calcifications. MRI has also become increasingly popular due to superior contrast resolution. Furthermore, the entire biliary tree, in particular the peripheral intrahepatic bile ducts and the distal part of the common bile duct, may be visualized on MRCP, while such visualization is difficult to see on US and CT.

Acknowledgements Open access funding provided by University of Fribourg.

Open Access This article is licensed under a Creative Commons Attribution 4.0 International License, which permits use, sharing, adaptation, distribution and reproduction in any medium or format, as long as you give appropriate credit to the original author(s) and the source, provide a link to the Creative Commons licence, and indicate if changes were made. The images or other third party material in this article are included in the article's Creative Commons licence, unless indicated otherwise in a credit line to the material. If material is not included in the article's Creative Commons licence and your intended use is not permitted by statutory regulation or exceeds the permitted use, you will need to obtain permission directly from the copyright holder. To view a copy of this licence, visit http://creativecommons.org/licenses/by/4.0/.

\section{References}

1. Rahimian J, Wilson T, Oram V, Holzman RS (2004) Pyogenic liver abscess: recent trends in etiology and mortality. Clin Infect Dis 39 (11):1654-1659. https://doi.org/10.1086/425616

2. Liu Y, Wang JY, Jiang W (2013) An Increasing Prominent Disease of Klebsiella pneumoniae Liver Abscess: Etiology, Diagnosis, and Treatment. Gastroenterol Res Pract 2013:258514. https ://doi.org/10.1155/2013/258514

3. Seeto RK, Rockey DC (1996) Pyogenic liver abscess. Changes in etiology, management, and outcome. Medicine (Baltimore) 75 (2):99-113. https://doi.org/10.1097/00005792-19960 3000-00006

4. Okano H, Shiraki K, Inoue H, Kawakita T, Yamamoto N, Deguchi M, Sugimoto K, Sakai T, Ohmori S, Murata K, Nakano T (2002) Clinicopathological analysis of liver abscess in Japan. Int J Mol Med 10 (5):627-630

5. Siu LK, Yeh KM, Lin JC, Fung CP, Chang FY (2012) Klebsiella pneumoniae liver abscess: a new invasive syndrome. Lancet Infect Dis 12 (11):881-887. https://doi.org/10.1016/s1473 -3099(12)70205-0

6. Fung CP, Chang FY, Lee SC, Hu BS, Kuo BI, Liu CY, Ho M, Siu LK (2002) A global emerging disease of Klebsiella pneumoniae liver abscess: is serotype $\mathrm{K} 1$ an important factor for complicated endophthalmitis? Gut 50 (3):420-424. https://doi.org/10.1136/ gut.50.3.420

7. Rossi B, Gasperini ML, Leflon-Guibout V, Gioanni A, de Lastours V, Rossi G, Dokmak S, Ronot M, Roux O, Nicolas-Chanoine MH, Fantin B, Lefort A (2018) Hypervirulent Klebsiella pneumoniae in Cryptogenic Liver Abscesses, Paris, France. Emerg Infect Dis 24 (2):221-229. https://doi.org/10.3201/eid2402.170957 
8. Czerwonko ME, Huespe P, Bertone S, Pellegrini P, Mazza O, Pekolj J, de Santibanes E, Hyon SH, de Santibanes M (2016) Pyogenic liver abscess: current status and predictive factors for recurrence and mortality of first episodes. HPB (Oxford) 18 (12):1023-1030. https://doi.org/10.1016/j.hpb.2016.09.001

9. Shi SH, Zhai ZL, Zheng SS (2018) Pyogenic Liver Abscess of Biliary Origin: The Existing Problems and Their Strategies. Semin Liver Dis 38 (3):270-283. https://doi.org/10.1055/s-0038-16613 63

10. Huang CJ, Pitt HA, Lipsett PA, Osterman FA, Jr., Lillemoe KD, Cameron JL, Zuidema GD (1996) Pyogenic hepatic abscess. Changing trends over 42 years. Ann Surg 223 (5):600-607; discussion 607-609. https://doi.org/10.1097/00000658-19960 5000-00016

11. Mortele KJ, Segatto E, Ros PR (2004) The infected liver: radiologic-pathologic correlation. Radiographics 24 (4):937-95510000, 10000. https://doi.org/10.1148/rg.244035719

12. Mathieu D, Vasile N, Fagniez PL, Segui S, Grably D, Larde D (1985) Dynamic CT features of hepatic abscesses. Radiology 154 (3):749-752. https://doi.org/10.1148/radiology.154.3.3969480

13. Gabata T, Kadoya M, Matsui O, Kobayashi T, Kawamori Y, Sanada J, Terayama N, Kobayashi S (2001) Dynamic CT of hepatic abscesses: significance of transient segmental enhancement. AJR Am J Roentgenol 176 (3):675-679. https://doi.org/10.2214/ ajr.176.3.1760675

14. Jeffrey RB, Jr., Tolentino CS, Chang FC, Federle MP (1988) CT of small pyogenic hepatic abscesses: the cluster sign. AJR Am J Roentgenol 151 (3):487-489. https://doi.org/10.2214/ajr.151.3.487

15. Alsaif HS, Venkatesh SK, Chan DS, Archuleta S (2011) CT appearance of pyogenic liver abscesses caused by Klebsiella pneumoniae. Radiology 260 (1):129-138. https://doi.org/10.1148/radio 1.11101876

16. Syed MA, Kim TK, Jang HJ (2007) Portal and hepatic vein thrombosis in liver abscess: CT findings. Eur J Radiol 61 (3):513-519. https://doi.org/10.1016/j.ejrad.2006.11.022

17. Molton JS, Chee YL, Hennedige TP, Venkatesh SK, Archuleta S (2015) Impact of Regional Vein Thrombosis in Patients with Klebsiella pneumoniae Liver Abscess. PLoS One 10 (10):e0140129. https://doi.org/10.1371/journal.pone.0140129

18. Akhan O, Pringot J (2002) Imaging of abdominal tuberculosis. Eur Radiol 12 (2):312-323. https://doi.org/10.1007/s003300100 994

19. Oto A, Akhan O, Ozmen M (1999) Focal inflammatory diseases of the liver. Eur J Radiol 32 (1):61-75. https://doi.org/10.1016/ s0720-048x(99)00115-1

20. Benedetti NJ, Desser TS, Jeffrey RB (2008) Imaging of hepatic infections. Ultrasound Q 24 (4):267-278. https://doi.org/10.1097/ ruq.0b013e31818e 5981

21. Denton T, Hossain J (1993) A radiological study of abdominal tuberculosis in a Saudi population, with special reference to ultrasound and computed tomography. Clin Radiol 47 (6):409-414. https://doi.org/10.1016/s0009-9260(05)81062-1

22. Yu RS, Zhang SZ, Wu JJ, Li RF (2004) Imaging diagnosis of 12 patients with hepatic tuberculosis. World J Gastroenterol 10 (11):1639-1642. https://doi.org/10.3748/wjg.v10.i11.1639

23. Brauner M, Buffard MD, Jeantils V, Legrand I, Gotheil C (1989) Sonography and computed tomography of macroscopic tuberculosis of the liver. J Clin Ultrasound 17 (8):563-568. https://doi. org/10.1002/jcu.1870170804

24. Hsieh TC, Wu YC, Hsu CN, Yang CF, Chiang IP, Hsieh CY, Sun SS, Kao CH (2011) Hepatic macronodular tuberculoma mimics liver metastasis in a patient with locoregional advanced tongue cancer. J Clin Oncol 29 (22):e641-643. https://doi.org/10.1200/ jco.2011.34.9407

25. Heller T, Belard S, Wallrauch C, Carretto E, Lissandrin R, Filice C, Brunetti E (2015) Patterns of Hepatosplenic Brucella
Abscesses on Cross-Sectional Imaging: A Review of Clinical and Imaging Features. Am J Trop Med Hyg 93 (4):761-766. https:// doi.org/10.4269/ajtmh.15-0225

26. Guo H, Wang Y, Yang Y, Liu W (2019) Hepatosplenic brucella abscesses on computed tomography and magnetic resonance imaging: Case series. Medicine (Baltimore) 98 (24):e15881. https ://doi.org/10.1097/md.0000000000015881

27. Sisteron O, Souci J, Chevallier P, Cua E, Bruneton JN (2002) Hepatic abscess caused by Brucella US, CT and MRI findings: case report and review of the literature. Clin Imaging 26 (6):414417. https://doi.org/10.1016/s0899-7071(02)00507-7

28. Hopkins KL, Simoneaux SF, Patrick LE, Wyly JB, Dalton MJ, Snitzer JA (1996) Imaging manifestations of cat-scratch disease. AJR Am J Roentgenol 166 (2):435-438. https://doi.org/10.2214/ ajr.166.2.8553962

29. Danon O, Duval-Arnould M, Osman Z, Boukobza B, Kazerouni F, Cadranel JF, Neuenschwander S, Nocton F (2000) Hepatic and splenic involvement in cat-scratch disease: imaging features. Abdom Imaging 25 (2):182-183. https://doi.org/10.1007/s0026 19910040

30. Ryder SD, Beckingham IJ (2001) ABC of diseases of liver, pancreas, and biliary system: Chronic viral hepatitis. BMJ 322 (7280):219-221. https://doi.org/10.1136/bmj.322.7280.219

31. Rofsky NM, Fleishaker H (1995) CT and MRI of diffuse liver disease. Semin Ultrasound CT MR 16 (1):16-33. https://doi. org/10.1016/0887-2171(95)90012-8

32. van Breda Vriesman AC, Engelbrecht MR, Smithuis RH, Puylaert JB (2007) Diffuse gallbladder wall thickening: differential diagnosis. AJR Am J Roentgenol 188 (2):495-501. https://doi. org/10.2214/ajr.05.1712

33. Mortele KJ, Ros PR (2002) MR imaging in chronic hepatitis and cirrhosis. Semin Ultrasound CT MR 23 (1):79-100. https://doi. org/10.1016/s0887-2171(02)90030-2

34. Schedel H, Wicht L, Rogler G, Langer R, Felix R (1994) [CTmorphologic aspects of the liver in patients with HIV infection]. Aktuelle Radiol 4 (4):188-191

35. Bilgin M, Balci NC, Erdogan A, Momtahen AJ, Alkaade S, Rau WS (2008) Hepatobiliary and pancreatic MRI and MRCP findings in patients with HIV infection. AJR Am J Roentgenol 191 (1):228-232. https://doi.org/10.2214/ajr.07.3197

36. Pastakia B, Shawker TH, Thaler M, O’Leary T, Pizzo PA (1988) Hepatosplenic candidiasis: wheels within wheels. Radiology 166 (2):417-421. https://doi.org/10.1148/radiology.166.2.3275982

37. Berlow ME, Spirt BA, Weil L (1984) CT follow-up of hepatic and splenic fungal microabscesses. J Comput Assist Tomogr 8 (1):42-45. https://doi.org/10.1097/00004728-198402000-00009

38. Semelka RC, Shoenut JP, Greenberg HM, Bow EJ (1992) Detection of acute and treated lesions of hepatosplenic candidiasis: comparison of dynamic contrast-enhanced CT and MR imaging. J Magn Reson Imaging 2 (3):341-345. https://doi.org/10.1002/jmri.1880020315

39. Sharma R, Lipi L, Gajendra S, Mohapatra I, Goel RK, Duggal R, Mishra SR, Gautam D (2017) Gastrointestinal Histoplasmosis: A Case Series. Int J Surg Pathol 25 (7):592-598. https://doi. org/10.1177/1066896917709945

40. Marrone G, Crino F, Caruso S, Mamone G, Carollo V, Milazzo M, Gruttadauria S, Luca A, Gridelli B (2012) Multidisciplinary imaging of liver hydatidosis. World J Gastroenterol 18 (13):14381447. https://doi.org/10.3748/wjg.v18.i13.1438

41. Beggs I (1985) The radiology of hydatid disease. AJR Am J Roentgenol 145 (3):639-648. https://doi.org/10.2214/ajr.145.3.639

42. Lewall DB (1998) Hydatid disease: biology, pathology, imaging and classification. Clin Radiol 53 (12):863-874. https://doi. org/10.1016/s0009-9260(98)80212-2

43. Bachler P, Baladron MJ, Menias C, Beddings I, Loch R, Zalaquett E, Vargas M, Connolly S, Bhalla S, Huete A (2016) Multimodality Imaging of Liver Infections: Differential Diagnosis and Potential 
Pitfalls. Radiographics 36 (4):1001-1023. https://doi.org/10.1148/ rg.2016150196

44. Doyle DJ, Hanbidge AE, O'Malley ME (2006) Imaging of hepatic infections. Clin Radiol 61 (9):737-748. https://doi.org/10.1016/j. crad.2006.03.010

45. Polat P, Kantarci M, Alper F, Suma S, Koruyucu MB, Okur A (2003) Hydatid disease from head to toe. Radiographics 23 (2):475-494; quiz 536-477. https://doi.org/10.1148/rg.232025704

46. Pedrosa I, Saiz A, Arrazola J, Ferreiros J, Pedrosa CS (2000) Hydatid disease: radiologic and pathologic features and complications. Radiographics 20 (3):795-817. https://doi.org/10.1148/radio graphics.20.3.g00ma06795

47. Katranci N, Elmas N, Yilmaz F, Mentes A (1999) Correlative CT, MRI and histological findings of hepatic Echinococcus alveolaris: a case report. Comput Med Imaging Graph 23 (3):155-159. https ://doi.org/10.1016/s0895-6111(99)00004-x

48. Vilgrain V (2001) [Cystic lesions of the liver]. Gastroenterol Clin Biol 25 (4 Suppl):B167-177

49. Czermak BV, Akhan O, Hiemetzberger R, Zelger B, Vogel W, Jaschke W, Rieger M, Kim SY, Lim JH (2008) Echinococcosis of the liver. Abdom Imaging 33 (2):133-143. https://doi.org/10.1007/ s00261-007-9331-0

50. Kern P, Menezes da Silva A, Akhan O, Mullhaupt B, Vizcaychipi KA, Budke C, Vuitton DA (2017) The Echinococcoses: Diagnosis, Clinical Management and Burden of Disease. Adv Parasitol 96:259-369. https://doi.org/10.1016/bs.apar.2016.09.006

51. Marani SA, Canossi GC, Nicoli FA, Alberti GP, Monni SG, Casolo PM (1990) Hydatid disease: MR imaging study. Radiology 175 (3):701-706. https://doi.org/10.1148/radiology.175.3.2343117

52. Mehta P, Prakash M, Khandelwal N (2016) Radiological manifestations of hydatid disease and its complications. Trop Parasitol 6 (2):103-112. https://doi.org/10.4103/2229-5070.190812

53. Balli O, Balli G, Cakir V, Gur S, Pekcevik R, Tavusbay C, Akhan O (2019) Percutaneous Treatment of Giant Cystic Echinococcosis in Liver: Catheterization Technique in Patients with CE1 and CE3a. Cardiovasc Intervent Radiol 42 (8):1153-1159. https://doi. org/10.1007/s00270-019-02248-z

54. Brunetti E, Tamarozzi F, Macpherson C, Filice C, Piontek MS, Kabaalioglu A, Dong Y, Atkinson N, Richter J, SchreiberDietrich D, Dietrich CF (2018) Ultrasound and Cystic Echinococcosis. Ultrasound Int Open 4 (3):E70-E78. https://doi. org/10.1055/a-0650-3807

55. Kodama Y, Fujita N, Shimizu T, Endo H, Nambu T, Sato N, Todo S, Miyasaka K (2003) Alveolar echinococcosis: MR findings in the liver. Radiology 228 (1):172-177. https://doi.org/10.1148/ radiol.2281020323

56. Claudon M, Bessieres M, Regent D, Rodde A, Bazin C, Gerard A, Bresler L (1990) Alveolar echinococcosis of the liver: MR findings. J Comput Assist Tomogr 14 (4):608-614. https://doi. org/10.1097/00004728-199007000-00018

57. Haque R, Huston CD, Hughes M, Houpt E, Petri WA, Jr. (2003) Amebiasis. N Engl J Med 348 (16):1565-1573. https://doi. org/10.1056/nejmra022710

58. Radin DR, Ralls PW, Colletti PM, Halls JM (1988) CT of amebic liver abscess. AJR Am J Roentgenol 150 (6):1297-1301. https:// doi.org/10.2214/ajr.150.6.1297

59. Elizondo G, Weissleder R, Stark DD, Todd LE, Compton C, Wittenberg J, Ferrucci JT, Jr. (1987) Amebic liver abscess: diagnosis and treatment evaluation with MR imaging. Radiology 165 (3):795-800. https://doi.org/10.1148/radiology.165.3.2891154

60. Kurland JE, Brann OS (2004) Pyogenic and amebic liver abscesses. Curr Gastroenterol Rep 6 (4):273-279. https://doi. org/10.1007/s11894-004-0078-2

61. Tandon A, Jain AK, Dixit VK, Agarwal AK, Gupta JP (1997) Needle aspiration in large amoebic liver abscess. Trop Gastroenterol 18 (1):19-21
62. Kunze G, Staritz M, Kohler M (2015) Contrast-enhanced ultrasound in different stages of pyogenic liver abscess. Ultrasound Med Biol 41 (4):952-959. https://doi.org/10.1016/j.ultrasmedb io.2014.12.001

63. Manzella A, Ohtomo K, Monzawa S, Lim JH (2008) Schistosomiasis of the liver. Abdom Imaging 33 (2):144-150. https://doi. org/10.1007/s00261-007-9329-7

64. Dusak A, Onur MR, Cicek M, Firat U, Ren T, Dogra VS (2012) Radiological Imaging Features of Fasciola hepatica Infection - A Pictorial Review. J Clin Imaging Sci 2:2. https://doi. org/10.4103/2156-7514.92372

65. Lim JH, Kim SY, Park CM (2007) Parasitic diseases of the biliary tract. AJR Am J Roentgenol 188 (6):1596-1603. https://doi. org/10.2214/ajr.06.1172

66. Teke M, Onder H, Cicek M, Hamidi C, Goya C, Cetincakmak MG, Hattapoglu S, Ulger BV (2014) Sonographic findings of hepatobiliary fascioliasis accompanied by extrahepatic expansion and ectopic lesions. J Ultrasound Med 33 (12):2105-2111. https:// doi.org/10.7863/ultra.33.12.2105

67. Kabaalioglu A, Cubuk M, Senol U, Cevikol C, Karaali K, Apaydin A, Sindel T, Luleci E (2000) Fascioliasis: US, CT, and MRI findings with new observations. Abdom Imaging 25 (4):400-404. https://doi.org/10.1007/s002610000017

68. Kabaalioglu A, Ceken K, Alimoglu E, Saba R, Cubuk M, Arslan G, Apaydin A (2007) Hepatobiliary fascioliasis: sonographic and CT findings in 87 patients during the initial phase and long-term follow-up. AJR Am J Roentgenol 189 (4):824-828. https://doi. org/10.2214/ajr.07.2127

69. Gonzalo-Orden M, Millan L, Alvarez M, Sanchez-Campos S, Jimenez R, Gonzalez-Gallego J, Tunon MJ (2003) Diagnostic imaging in sheep hepatic fascioliasis: ultrasound, computer tomography and magnetic resonance findings. Parasitol Res 90 (5):359-364. https://doi.org/10.1007/s00436-003-0866-x

70. Das AK (2014) Hepatic and biliary ascariasis. J Glob Infect Dis 6 (2):65-72. https://doi.org/10.4103/0974-777x.132042

71. Khuroo MS, Zargar SA, Mahajan R (1990) Hepatobiliary and pancreatic ascariasis in India. Lancet 335 (8704):1503-1506. https ://doi.org/10.1016/0140-6736(90)93037-p

72. Pinilla AE, Lopez MC, Ricaurte O, Castillo B, Murcia MI, Nicholls RS, Duque S, Orozco LC (2001) Liver abscess caused by Ascaris lumbricoides: case report. Rev Inst Med Trop Sao Paulo 43 (6):343-346. https://doi.org/10.1590/s0036-466520010006000 10

73. Kubaska SM, Chew FS (1997) Biliary ascariasis. AJR Am J Roentgenol 169 (2):492. https://doi.org/10.2214/ajr.169.2.92427 60

74. Lim JH (1990) Radiologic findings of clonorchiasis. AJR Am J Roentgenol 155 (5):1001-1008. https://doi.org/10.2214/ ajr.155.5.2120925

75. Lee SH, Shim TS, Lee SM, Chi JG (1978) [Studies On Pathological Changes Of The Liver In Abino Rats Infected With Clonorchis Sinensis]. Kisaengchunghak Chapchi 16 (2):148-155. https://doi. org/10.3347/kjp.1978.16.2.148

76. Jeong YY, Kang HK, Kim JW, Yoon W, Chung TW, Ko SW (2004) MR imaging findings of clonorchiasis. Korean J Radiol 5 (1):25-30. https://doi.org/10.3348/kjr.2004.5.1.25

77. Choi D, Hong ST (2007) Imaging diagnosis of clonorchiasis. Korean J Parasitol 45 (2):77-85. https://doi.org/10.3347/ kjp.2007.45.2.77

78. Choi BI, Han JK, Hong ST, Lee KH (2004) Clonorchiasis and cholangiocarcinoma: etiologic relationship and imaging diagnosis. Clin Microbiol Rev 17 (3):540-552, table of contents. https://doi. org/10.1128/cmr.17.3.540-552.2004

Publisher's Note Springer Nature remains neutral with regard to jurisdictional claims in published maps and institutional affiliations. 